\title{
What Influences Implementation Intentions in an Academic Learning Context - The roles of Goal Intentions, Procrastination, and Experience
}

\author{
Lutz Sommer \& Manuel Haug \\ Albstadt-Sigmaringen University \\ Department of Business Administration and Engineering \\ Jakobstr. 1 - 72458 Albstadt, Germany \\ Tel: 49-7571-732-9531Ｅ-mail: sommer@hs-albsig.de
}

Received: February 27, 2012

Accepted: April 19, 2012

Published: May 15, 2012

doi:10.5430/ijhe.v1n1p32

URL: http://dx.doi.org/10.5430/ijhe.v1n1p32

\begin{abstract}
Studies show that many students struggle with properly organizing their academic activities; what makes things even worse is that up to $90 \%$ of students are at least part-time procrastinators. In order to clarify how these students could be supported, the article at hand deals with the influences and possible benefits of implementation intentions in an academic learning context and substantiates the literature discussion with data collected among students. Aiming at studying the antecedents of academic performance from a cognitive perspective, the research complements an extended form of the Theory of Planned Behaviour by integrating procrastination and experience. Unlike many other studies, this paper does not focus on reasons for nor different forms of procrastination, but rather develops a comprehensive framework for understanding academic learning. A structural equation modelling approach is applied for this purpose using an empirical data base. For the outcome of this research different hypotheses are investigated especially in reference to implementation intentions. In the majority of cases the theories presented during the literature review can be substantiated with the empirical data used for the study. Key findings are the significant influences of goal intentions, as well as experience, and their positive effect on implementation intentions. Furthermore, the negative influence of procrastination is underlined by the results of the paper and identified as a major problem for college students. Other findings of the paper are the effects of subjective norms and PBC (Perceived Behaviour Control) on the formation of goal intentions. Nevertheless, the study brings up several further questions and identifies areas where research should be deepened, that is behaviour itself.
\end{abstract}

Keywords: Experience, Procrastination, Implementation intentions, Behaviour, Academic learning

\section{Introduction}

It is desirable, both from societal and individual points of view, to increase the rate of successful students. Modern, knowledge-oriented societies have a large demand for information. Hence, people are needed who are familiar with analysing complex situations. Not surprisingly, today's labour markets tend to show a considerable need for graduates (Kistan, 2002). While graduates apparently face relatively good opportunities on today's labour markets, studying itself seems to entail a lot of challenges for students. In 2011, the Pearson Foundation has conducted the Community College Students Survey across the USA (Pearson, 2011). Interestingly, about 15 percent of the interviewed students said that already had dropped out or at least seriously considered doing so within the first semester. The main reasons are struggles with courses or properly organizing the total workload induced by university, family, and work obligations. What is even more interesting: even when facing considerable difficulties, many students are not able to seek the support needed to successfully complete their studies. Furthermore, a study on counselling needs of students conducted at medium-sized suburban institution (Bishop, Bauer, \& Becker, 1998) revealed that about $50 \%$ of students indicated an at least medium-level need for assistance with organizing time available and dealing with test anxiety and poor studying behaviour. Furthermore, about one third of students face considerable challenges in terms of fear of failure, depression, panic, and public speaking anxiety. Of course, such difficulties can lead to academic failure or - as mentioned above dropping the studies. As shown above, from a labour market or even societal point of view, the share of failed students should be as low as possible.

Also on individual level, it is important to avoid negative consequences of academic failure such as psychic problems or unemployment. This raises the question of the main influences on academic success. Beyond doubt, how students study 
and prepare themselves for exams is a key element. Hence, understanding the determinants of this behaviour is necessary to increase the rate of both successful students and share of graduates in modern societies. As the immediate antecedents to behaviour are cognitive in nature, a cognitive perspective on preparation seems reasonable.

Addressing this aspect also implies that factors interfering with goal-directed learning have to be taken into consideration. One aspect of particular relevance in this context is procrastination, which has been described as the intended delaying or postponement of decision-making or implementing a decision already made (for example Ferrari, 2001). To get an impression of the phenomenon's meaning: between $50 \%$ and $95 \%$ of college students are at least temporarily engaged in procrastination (Day, Mensik, \&O'Sullivan, 2000). These numbers are even more compelling when taking into consideration the results of academic procrastination. They range from observable aspects such as low grades (Wesley, 1994) and different forms of cheating (Roig\&DeTommaso, 1995) to psychological issues such as anxiety (Rothblum, Solomon, \& Murakami, 1986) and low self-esteem (cf. Ferrari, 1992). Even depression (Solomon \&Rothblum, 1984) can result from procrastination. In the final consequence, procrastination with respect to for example writing can lead to low-level jobs (cf. Fritzsche, Young, \&Hickson, 2003; Koretz, 1997). While procrastination apparently may have many negative consequences, in the context of this paper especially poor performance in class exercises, final exams and lower course grades have to be mentioned (cf. Owens \&Newbegin, 1997).

This paper does not - unlike many others - examine the reasons and different forms of procrastination. In fact, most of procrastination literature is focusing on causes of procrastination and how to overcome it (Owens, Bowman, \&Hill, 2008). Hence, little is known on how procrastination affects the cognitive process which precedes the learning or preparing for exams behaviour. This paper will highlight how procrastination and other cognitive factors affect the development of the immediate cognitive antecedent to behaviourthat is intention. Here, a sound and robust theory perspective is necessary. The best-known - and at the same time well-examined - research perspective in this case is the Theory of Planned Behaviour (Ajzen, 1991). It has been successfully applied tomany different behaviours. The applications range from health care to marketing (Shepperd et al., 1988; Kim, \&Hunter, 1993; Kalafatis et al., 1999). Theory of Planned Behaviour has also been suggested to be a good framework for analysing learning behaviour (Prentice, Caska,\&McLaughlin, 2009). Research has shown, that while explained variance with intentions generally is high, it is much lower for behaviour (Armitage\&Conner, 2001). Fortunately, it is open to the inclusion of new elements, provided that they add to the share of explained variance. One extension, which seems to be of particular relevance are implementation intentions, as this construct helps to explain why even strong intentions very often do not lead to behaviour. Last but not least: TPB also has been used in conjunction with procrastination and proven to be a good base for analysing this phenomenon (cf. Lay/Burns, 1991; Sirois, 2004).

The paper at hand will pursue the following goals. First, it will develop an extended theoretical model of TPB which integrates procrastination, implementation intentions and another aspect which deserves researchers' attention in this context: students' experience with the subject. Second, only a limited number of studies have examined procrastination and implementation intentions at the same time. Very often, the effects of procrastination on the intention-behaviour-link have been investigated. Whether or not procrastination even interferes with the natural development of implementation intentions still seems to be rather poorly investigated. As the latter have been described as an important means to increase the likelihood of showing certain behaviour (Van Hooft et al., 2005), this aspect is particularly relevant. The paper at hand will address this issue. As the study at hand focuses on the influences of certain factors on different types of intentions, behaviour itself is not directly addressed in order to reduce complexity. Third, research has shown that the relative importance of TPB constructs varies over different behaviours. Thus, this study also aims at clarifying the relative importance of each of the model's elements in the learning/preparation for exams context. Fourth, reaching the goals mentioned above will yield a context-specific model explaining which cognitive factors facilitate and which interfere with the development of learning behaviour. This model will help teaching faculty to develop individual-level interventional strategies to improve their students' preparational measures and eventually academic success.

The paper is structured as follows. In the second chapter, research findings so far will be presented, which will be integrated into a research model. Both the model and the hypotheses are described in section 3.The next part is dedicated to the methodology, while the presentation of empirical results as well as the discussion of the findings are left to section 5. Part 6 summarizes the paper in the form of conclusions, practical implicationsand avenues for future research, while the last section discusses statistical limitations.

\section{Literature Review}

\subsection{The Theory of Planned Behaviour}

Basically, the question of how students can be brought to prepare themselves properly for exams is a question of student motivation. In recent years, there was an intense discussion in literature on the motivation of students (Winn, 2002). 
Psychology has described several strategies which help students increase motivation for learning and preparing for exams (Newstead, 1998). As for examination performance it has been found that the personality aspect is a promising research avenue (Philips et al., 2003). A five factor model proved to be good in terms of predicting examination results. It comprises extraversion, neuroticism, openness, conscientiousness and agreeableness (Goldberg, 1993; Digman, 1990; McCrae, \&John, 1992). But despite the fact that these traits are good predictors, it remains unclear how exactly they influence study results. Goal-specific cognitiveapproachesbecome relevant in this context, as they also provide insights into how psychological foundations lead to achievement-oriented cognitions (Evans et al., 1988; Hampson, 1999) and eventually to action itself. On the other hand it surely is not sufficient to only look at cognitions in the examination context. Due to the rapidly declining motivation and fulfilling intentions of students, it seems to be more advisable to maintain or strengthen students' early enthusiasm for academic work and help them develop skills for continuous learning (Winn, 2002). As intention is a factor very close to actual behaviour, this construct seems to be an important starting point. The Theory of Planned Behaviour (Ajzen, 1991) is intention-oriented and also a successfully applied model of goal-specific cognition (Philips et al., 2003).

Theory of Planned Behaviour and its ancestor, the Theory of Reasoned Action (TRA) are the best-known models of the expectancy-value approach with respect to the attitude-behaviour relationship (Tesser\&Shaffer, 1990). Human behaviour is guided by different subjective probabilities (e.g. Fishbein\&Ajzen, 1975), that means beliefs about the consequences of behaviour, beliefs about the normative expectations of other people and beliefs about the presence of factors which may facilitate or impede performance of behaviour. Beliefs are based on a wide range of background factors. In their aggregates, behavioural beliefs produce attitude towards behaviour, normative beliefs result in subjective norms and control beliefs generate perceived behaviour control (Fishbein\&Ajzen, 1975). Theory of Planned Behaviour is based on the Theory of Reasoned Action (Fishbein\&Ajzen, 1975). Actually, it represents an extension as PBC has been included as an additional element. Theory of Reasoned Action assumes that an individual has full volitional control over certainbehaviour. This is not the case for many types of behaviour today (Ajzen, 1988). While attitude and subjective norm exert influence on behaviour only indirectly via intention, PBC very often, but not always, shows an impact on both intention and behaviour. The direct effect then stems from its characteristic of being a partial substitute for actual control (Ajzen\&Madden, 1986). In other words: the effect of PBC depends on whether or not it is good proxy for actual control. This, for example, is not given in cases where the behaviour in question is rather new to the individual. It is important to note that PBC resembles to a certain extent Bandura's concept of self-efficacy (Bandura, 1982). But while self-efficacy is more or less internallyfocused - what does one believe he/she can achieve on his/her own - PBC does also take into consideration external factors which may hinder or support the achievement of a desired goal (Van Hooft et al., 2005).

The combination of all these elements leads to the formation of a behavioural intention (Ajzen, 2002, p. 107). Behavioural intention could be described as "... instructions that people give to themselves to behave in certain way" (Triandis, 1980, p. 203). In other words, intention reflects motivation and indicates how hard an individual will try to achieve a desired outcome (Webb\&Sheeran, 2005). Intention could be understood as an immediate antecedent to behaviour(Ajzen, 2002, p. 107). Figure 1 presents an overview of the interplay between the so-called background factors, beliefs, aggregates, intention and behaviour (Ajzen, 2005, p. 135):

--- place figure 1 here ---

Figure 1. Theory of Planned Behaviour

Source: Ajzen (2005), p. 135 - modified

Probably one of the most interesting aspects in the context of TPB is its openness to the inclusion of further constructs. It might be extended in case other factors increase the explained variance of intention or behaviour provided that the models of other variables have properly been taken into account (Ajzen 1991).

In order to get a deeper understanding of how intentions are translated into action, the Rubicon Model (Achtziger\&Gollwitzer 2006, pp. 277 et seqq.) is useful.

--- place figure 2 here ---

Figure 2 - Rubicon model - modified

Source: Achtziger, \& Gollwitzer(2006), p. 278

The followingexplanatorynotesare based on the Rubicon Model (Gollwitzer, 1986; Achtziger\&Gollwitzer, 2006, pp. 277 et seqq.): 
Selection: $\quad$ Several different desires are compared, which due to existing restrictions cannot be followed simultaneously. Developing an intention means that sort of a commitment towards reaching the selected goal is given. Hence, this step represents crossing the Rubicon.

Pre-action: In this phase, the individual develops a plan, that is where, when, and how of behavioural enactment are defined. Which intention is followed depends on the volitional strength ofeachbehaviour. This, in turn, is influenced by aspects such as feasibility and situational restrictions.

Action: Behaviour is performed consequently in order to reach the defined goal. Interfering influences are excluded as far as possible. Furthermore, delimitation from alternative intentions takes place.

Post-Action: Goal attainment is evaluated.

The Rubicon model indicates that the process of developing and implementing intentions is rather complex. As this paper deals - among other aspects - with the question of how the process of transforming goal intentions into action can be supported, theoretical approaches focusing on how people change should be included. Referring to addictive behaviours, Prochaska, DiClemente and Norcross (1992)have presented a model which describes how addicts go through different phases in order to at least develop the motivation to change their behaviour and continuously translate the latter into action. Based on extensive field research, they argue that self-initiated and externally facilitated change requires successfully passing five different phases:

- Precontemplation: in this phase, most of the addicts are not even aware that they really have a problem. Consequentially, they are far from having an intention to change. Compared to the Rubicon model, this phase even precedes the selection phase as here simply the main influence for even forming a motivation to act is missing: awareness for a necessary behavioural action.

- Contemplation: here, people have successfully taken a small, yet important step - they know, that they have an addiction problem and should change their behaviour. However, even in this stage, no formal commitment has been built up. As the authors state in their seminal paper, this group of addicts can be described as "knowing where you want to go but not quite ready yet" (Prochaska, DiClemente, \&Norcross, 1992, p. 1103). Therefore, this phase as well precedes the formation-of-intention-stage in the Rubicon model.

- Preparation: this stage the authors originally described as decision-making phase, which therefore is somewhat similar to the Rubicon model's selection-step.Individuals who are in the preparation phase have successfully developed the intention to change their behaviour. Very often, they have even started some concrete, yet little, unsystematic activities to do so. In each case, people in this stage have successfully generated an intention or motivation, respectively, and are making plans to implement it. However, they "have not yet reached a criterion for effective action" (Prochaska, DiClemente, \&Norcross, 1992, p. 1104). Motivation has been described as indispensable element in overcoming addiction (cf. Miller, 1998). As the Rubicon model's pre-action phase deals with developing plans for implementing a decision, there are also some parallels with this stage.

- Action: people in this stage are described as actively changing their behaviour. However, action and successful change must not be confused, as the latter is rather the result of the former. Addicts are said to be in this stage in case they have successfully managed to modify their behaviour for a period of time ranging from one day to six months. This phase clearly is to a large extent congruent to the Rubicon model's action phase.

- Maintenance: this stage can be described as "continuation of change" (Prochaska, DiClemente, \&Norcross, 1992, p. 1104), i.e. people are trying to keep themselves on track and avoid relapses. In other words, they are making effort to secure the gains already made. Having successfully avoided the addictive behaviour for at least six months qualifies an individual for belonging to this group. As people here at least implicitly evaluate their activities of change in order to get an impression how successful they are in changing their behaviour, this phase is somewhat congruent to the Rubicon model's post action phase.

Prochaska and his colleagues (1992) have made the case that addicts who successfully change their behaviour in the first attempt are rather the exception than the rule. Most of them have to try several times before they reach their goals; some of them never manage to get them implemented. Hence, the process of change does follow a strict linear course only in very specific cases. For most individuals, it should be conceived as a spiral pattern where relapse implies going back to an earlier stage. An instrument of particular relevance for promoting change is motivational interviewing (Miller\&Rollnick, 1991). It can be described as "collaborative, person-centered form of guiding to elicit and strengthen motivation for change" (Miller \&Rollnick, 2009, p. 137). The approach implies that a person serving as a counselor for addicts should avoid forcing the addict to show a certain behavior. Rather, counselors should stay in the background in order to minimize resistance. Summarizing this brief outline, it can be argued that it takes two preliminary phases for an addict to even develop the motivation to change. As addiction can be described as a rather harmful, deleterious behavior, 
it has some parallels with procrastination. Furthermore, the authors here refer - rather indirectly - to the necessity of supporting instruments helping translate the intention into action.In other words: this approach, too, underlines the critical role of strategies closing the gap between (goal) intention and behavior. Interestingly, in another study, self-efficacy has been identified to be an important influence when addicts are progressing to the next phase (Prochaska et al., 1985). Please note that this is an element which can be compared to the factor which in TPB (Van Hooft et al., 2005) very often shows the strongest effect: PBC.

Interestingly, one of the earliest studies dealing with TPB was done with the intention to predict students' grades (Ajzen\&Madden, 1986). A strong determination to get a good mark at the end of the course had a significantly positive effect on the students' performance. Perceived Behaviour Control was relevant when measures were taken one week prior to the exams. Theory of Planned Behaviours strong predictive power in this context was confirmed by other studies (e.g. Manstead\&Van Eekelen, 1998; Prentice et al., 2009). Also, study behaviours in general have been examined using TPB. As an example, the paper by Leone and colleagues (1999) showed that more than $50 \%$ of variance with respect to the amount of time spent for studying is explained by TPB. Furthermore, an early paper by Lay and Burns (1991) investigated to what extent TPB accurately predicts the effort students are willing to invest in order to prepare for exams. Interestingly, their overall model did not support the thesis, that attitude, subjective norm and PBC do predict intention. However, when segregating the explained variable in intended hours per day and intended number of days, respectively, the variables turned out to be relevant. Despite all the equivocality about the relevance of the main variables, the authors found support for intention being the best predictor of behaviour. Several other studies, too, applying TPB to the educational sector found that intention is an important determinant of educational outcome (Graham et al., 1995; Morgan, 1985; Webb et al., 2007). Generally, the relationship between intention and behaviour is rather large in educational settings (Cohen, 1992; Webb et al., 2007). However, several studies in this particular field also showed that extensions of TPB seem to make sense. Preparing for exams is a rather complex behaviour - one has to make a schedule and to decide what is important for the exam. Hence, other variables may be relevant as well in this particular context. As an example, Phillips and her colleagues (2004) found that intention and PBC are very good predictors of examination results. However, attitudes in their paper were not a significant determinant of intentions. Aspects such as anticipated regret or a good-student identity were. Interestingly, the paper by Phillips and colleagues (2004) stated that certain traits have effects on the results, but actually all of them were mediated. The paper in question had an explained variance with respect to the results of $32 \%$ which is rather good. Other authors, too, tried to increase explained variance by extending the basic TPB framework and did get encouraging results. Prentice and his research colleagues (2009) included aspects such as anxiety. Lay and Burns back in 1991 could improve predictive strengthby integrating traits such as optimism.

\subsection{Implementation Intentions}

Another extension which has been implemented in a wide range of behavioursare implementation intentions (Gollwitzer, 1993; 1996). Complementing TPB by this element is mainly based on the consideration that TPB on the one hand covers the motivation to act - this can be called "goal intention"- but on the other hand itdoes not say how the latter leads to action (cf. Bagozzi, 1992). This is the reason why Gollwitzer (1993) has introduced the implementation intention construct. It can be described as a self-regulatory tool to achieve goals already set (Gollwitzer, 1996; 1999). The distinction between goal and implementation intentions is based on an analysis of the cognitive process which eventually leads to action. According to Gollwitzer (1990), there is a predecisional phase which sees the individual deliberate on which activity should be undertaken. The result of this phase - which shows a lot of parallels to Ajzen's concept of intention formation (Orbell et al., 1997) - is a goal intention. Hence, this part of the process is rather motivational in nature. What follows then is the postdecisional phase where the implementation of the goal is in the foreground; here volition is predominant. It is characterized by planning when, where, and how to act in order to reach the goal. To put it another way: an implementation plan is developed. The individual hence develops specific intentions which say that once a certain situation is encountered, the goal intention will be implemented. In other words: control is passed over to the situation specified in the implementation intention. There exists some sort of a mental link between a future situation and a goal directed response which has an "if-then" form - "if situation $\mathrm{x}$ is encountered, then I will perform behaviour Y” (Brandstätter et al., 2003, p. 41).In traditional theories goal intention is the immediate antecedent to goal achievement (Brandstätter et al., 2003). This view has to be extended - at least to a certain extent: the goal intention-behaviour link seems to be mediated by implementation intentions (Gollwitzer, 1993). Several other theories, for example the model of action phases (Heckhausen\&Gollwitzer, 1987) stress that goal intentions are followed by implementation intentions.

The relevance of implementation intentions in the context of this paper is twofold. First, from a theoretical point of view, there seems to exist an intention-action gap in TPB. An analysis of meta-analyses presented by Sutton (1998) showed that attitude, subjective norm and $\mathrm{PBC}$ explained large parts of intention but that predictive power with respect to 
behaviour is lower. This is why many authors stated that the way from goal intention to action remains rather unexplored (cf. Eagly\&Chaiken, 1993). Assuming that the process of making and implementing decisions is correct, implementation intentions contribute to close the gap between motivation and action. It has been confirmed at several occasions that implementation intentions have a strong grounding in theory (Armitage, 2004). From a statistical point of view, the construct is said to increase the likelihood of performing the behaviour in question (Van Hooft, 2005). The second aspect which underlines the relevance of the construct is the fact that it proved to be useful in practical applications. Webb et al. (2007) were the first who tested implementation intentions' relevance in a class-room context. They found that making plans helped students to turn up for class. It is straightforward to argue that this kind of intention also is useful to promote other daily activities of students, that is studying or preparing for exams, respectively (Webb et al., 2007). Furthermore, implementation intentions are easy-to-handle. In a basic application, all that is necessary is the individual thinking about the concrete circumstances under which the behaviour will be shown. This makes it a simple, quick to administer tool which avoids expensive changes in the environment (Gollwitzer et al., 2005). The instrument is also a very powerful tool as it overcomes a wide range of self-regulatory problems that may interfere in particular with students' daily business, for example attending class (Gollwitzer\&Sheeran, 2006).

Several studies - both experimental and field-oriented - have confirmed that implementation intentions lead to quick reaction and thus support goal achievement (Milne et al., 2002; Orbell et al.,1997; Sheeran\&Orbell, 2000). Not surprisingly, several studies have made use of implementation intentions in education-oriented settings. Webb and his colleagues (2007) have shown, that the construct helped students turn up for class - which is in most cases a clear precondition for performing well in the examination. Gollwitzer and Brandstätter (1997) tested the effect of implementation intentions in a series of university-based settings, for example doing assignments over Christmas Holidays. Implementation intentions helped individuals meet their assigned goals, but only in case they had access to specific resources such as relevant knowledge and skills. Brandstätter and her colleagues (2003) showed that among other factors, goal intention and implementation intention even exert a positive influence in a long-term setting, which focused on the question whether or not education should be continued.

\subsection{Procrastination}

An extension which seems to be of particular importance in the academic field is procrastination. It can be conceived as the tendency to delay those activities which are necessary to reach certain goals (Lay, 1986). Of course, it is not surprising that students especially in higher semesters have a rather large workload to cope with. Thus, it is clear that certain tasks have to be delayed simply because the necessary time budget is not available. This can be called intended delay. However, for procrastination the main criterion is that the postponement is unintended (Van Eerde, 2003). Procrastination, of course, is associated with a wide range of consequences. As an example, Ferrari and Emmons (1995) stated that procrastinators have problems with delaying gratification. Generally, they seem to prefer behaviours with short-term benefits at the cost of long-term profits (Baumeister\&Scher, 1988). Basically, procrastination can have two different forms. First, decisional procrastination is defined as dilatory behaviour when it comes to making important decisions (Ferrari et al., 1995).This has to be distinguished from avoidant or behavioural procrastination (Ferrari\&Emmons, 1994) which means that the individual in question avoids to perform a specific behaviour despite the fact that a corresponding decision already has been made - either by himself/herself or a third person or institution. Basically, procrastination also allows for another distinction to be made. While on the one hand, state-procrastination can be understood as sort of task-specific avoidance, an individual on the other hand may have the general problem of postponing steps to reach some goal - in this case, procrastination can be conceived as a trait (Schouwenburg, 2004). According to Van Eerde (2003), standard literature conceives procrastination as a lower-order personality trait. The paper at hand focuses on the distinction presented earlier, that is decisional versus avoidant behaviour.

The inclusion of procrastination into this research can be justified from two different points of view. First, it has theoretical relevance. Both forms of procrastination allow establishing some important links to TPB. It is straightforward to argue that decisional procrastination could interfere with developing a goal intention. Furthermore, behavioural procrastination might affect the translation of an intention into action. Empirical research, not surprisingly, found evidence for procrastinators actually having goal intentions but failing to implement them in a timely manner (Lay\&Brokenshire, 1997). Furthermore, they even have problems to act on strong goal intentions (Owens et al., 2008). This aspect clearly refers to the so-called intention-action gap mentioned above. Consequently, researchers have argued that in TPB models where procrastination is explicitly modelled, prediction of behaviour should be enhanced (Lay\&Burns, 1991). Interestingly, the latter study suggested that procrastination also might be a reflection of past behaviour or even habit. Then again, procrastination even seems to affect the step before. Sirois (2004) who investigated health behaviours showed that procrastination had a negative effect on health behaviour intentions. These lower intentions are due to a lower perceived competence. Lay et al. (1992) - going in a similar direction - argued that 
procrastination represents a limited range of behaviours which in turn could lead to a lower level of PBC. Procrastination therefore might be related to both goal intention and behaviour. Furthermore, there might also exist a link between procrastination and implementation intentions. Klassen and his colleagues (2008) argued that "in contrast to functional motivation variables like self-regulation, procrastination suggests lower levels of a motivated, planful approach to learning" (Klassen et al., 2008, p. 917). Not surprisingly, researchers have argued that procrastination cannot be fully understood unless goal and implementation intentions are considered at the same time (Owens et al., 2008). Second, procrastination is also relevant from a purely practical point of view. As already mentioned, about $70 \%$ of American college students are procrastinators (Hill et al., 1978). There is little doubt that this is also true for behaviours such as preparing for exams - Lay and his colleagues (1992) have described this phenomenon some twenty years ago.Several studies so far have tried to clarify the relationship between procrastination and academic performance. The paper of Lloyd and Knutzen (1969), dealing with properly programming undergraduate courses, is among the earliest contributions to the topic. It found that once students started performing an academic task, they stuck to it; however, there were considerable differences with respect to when students started. The researchers used course grade as dependent variable and found a strong negative influence of procrastination on the former. Schwartz (1976) investigated the time a student needed to accomplish a course. He found that the well-performing ones are unlikely to be procrastinators. Rothblum and his colleagues (1986) conducted a study which dealt with when students are taking quizzes during the semester. As dependent variables, grade point averages (GPA) over the semester were used, for which they obtained a strong negative correlation with procrastination. Owens and Newbegin in 1997 compared different ways to measure academic procrastination. First, they used Solomon and Rothblum's (1984) Procrastination Assessment Scale - Students (PASS), for which several studies found significant, albeit rather weak relationships with observed procrastination. Please note, that in Solomon and Rothblum's original study (1984), no relationship has been found. The second measurement used by Owens and Newbegin (1997) were teachers' evaluations of students' level of procrastination. When relating both measures to course grades in English and Maths, respectively, negative influences were discovered. Interestingly, teachers' estimations showed considerably stronger negative effects on the grades than the PASS measure. Beck and his colleagues (2000) did also apply a mixed approach, basing their study on PASS on the one hand and student self-reports on the other; the dependent used was exam grade. While analysing the former revealed that high procrastinators studied less than the others, the self-reported measures did not show any significant relationship with grades achieved. On the other hand, Rotenstein, Davis and Tatum (2009) investigated the effects of academic procrastination among MBA students. They used indirect measure of procrastination and two types of dependents: grades obtained for certain homework and final course grade, respectively. Even after controlling for student quality, significant negative effects have been found. Summarizing these studies, although some studies in the field did not find significant relationships, there indeed seem to exist negative influences of procrastination on academic performance.

Summarizing these considerations, it can be stated that procrastination is a common problem in academia and, furthermore, can be linked to TPB. Hence, when analysing the cognitive process that initiates studying, one clearly has to deal with procrastination.

\subsection{Experience}

As already mentioned, there seems to exist a gap between (goal) intention and behaviour. Many researchers concluded that some elements are apparently missing in the model and tried to enrich it by the inclusion of further constructs for example moral norms (McVea, 2009). One of the most interesting - and most intensely discussed - is Past Behaviour. Based on the Oxford Online Dictionary's (2011) definition of behaviour, it could be understood as actions or reactions of a person in the past in response to external or internal stimuli. The intersection of TPB and past behaviour has been extensively researched in the past few years, which is why a considerable body of literature is available today. As an example, more than 20 papers dealing with therelationship between both fields have been published in 2008 and 2009. Although Ajzen (1991) himself is rather sceptical when it comes to explicitly modelling past behaviour, there has been a lot of empirical support for taking into consideration the construct (Oullette\&Wood 1998). In contrast, habits generally have only few - if any - deliberative components; rather, they could be described as a goal-directed automatic behaviour which is shown as soon as certain external stimuli are present. Aarts et al. (1998) argue, that “...because of frequent performance in similar situations in the past, these mental representations and the resulting action can be automatically activated by environmental cues" (Aarts et al., 1998, p. 1359). Preparing for exams probably always is at least to a certain extent deliberated - and thus not fully automatized. This is why habit seems to be rather unimportant in the context of the paper at hand.

With respect to the preparing for exams behaviour, past behaviour actually has two components. First, it is related to the level of subject-relevant knowledge an individual has acquired in the past - this very likely has been gained in class or in earlier courses dealing with the same subject. The second element is the preparing behaviour itself; did the student make 
preparations for the same course or other courses with similar contents in the past? From a definition standpoint, the second aspect refers to past behaviour in a narrow sense while the first rather refers to a broader conceptualization of past behaviour. It is straightforward to argue that both components probably influence how students prepare themselves for exams. The more they already know about the subject, the less effort they have to do in order to acquire the level of knowledge necessary for the exam. Furthermore, the more often they have prepared themselves for exams in general and the subject in question in particular, the more they probably are aware of how to effectively and efficiently preparing for the test.

As already mentioned above, past behaviour seems to be a relevant construct also from a theoretical point of view. According to Bagozzi (1992), past behaviour can be segregated into two parts, that is frequency and recency. The former refers to how often a specific behaviour has been shown at all while the latter is linked to how often in the recent past the behaviour has been performed. It has been argued that both can influence goal intention and behaviour (Bagozzi\&Warshaw, 1992); however the concrete effects depend on the situation in question. Fazio and Williams (1986) found evidence for effects of frequency on goal intention in case attitude and subjective norm effects are unclear. Direct effects on behaviour may be due to badly formed intentions or when the specific behaviour has to be shown far in the future (Bagozzi\&Warshaw, 1992). Recency can directly influence present behaviour in case the latter depends on evaluations of past performance.Furthermore, direct effects on intention seem to be due to aspects such as availability or heuristic decision-making (Tversky\&Kahneman, 1974). Not surprisingly, the individual's decision as well as its implementation seem to be stronger influenced by recency information as it is more easily available (Leone et al., 2005).

As already mentioned, empirical relevance for past behaviour has been found for several contexts. These include breakfast consumption (Wong \&Mullan, 2009), recycling behaviour (Knussen et al., 2004), exercise behaviour (Rhodes \&Courneya, 2003) or dieting (Bagozzi\&Kimmel, 1995). Also in an academic setting, promising results have been obtained. Leone and his colleagues (1999) have studied the effects of having performed studying activities in the past on undergraduate students' current studying behaviour. They compared TRA, TPB and Theory of Self-regulation (TSR) by Bagozzi (1992) to each other. Empirical relevance of past behaviour was strong for TRA, but also for TPB. Despite the fact that in the case of TPB, PBC seems to tap a considerable part of past behaviour, the latter remained a relevant construct in the authors' augmented TPB model.

\section{Hypotheses Development}

According to Ajzen (1991, p. 188) an attitude is the "degree to which a person has a favourable or unfavourable evaluation or appraisal of the behaviour in question"; hence, attitude must not be confused with a general overall evaluation. The more an individual holds a positive evaluation of the behaviour in question, the higher the motivation of performing the behaviour is (Ajzen 1991). For many different kinds of behaviours, attitude has been found to be of particular relevance with respect to explained variance in intention (Armitage\&Conner, 2001). As for the study at hand, researchers have argued that aspects such as personality (Ehrman\&Oxford, 1995), emotions (Murrell, \&Bishop, 1995), attitudes (Dolan, 1999) and others exert influence on students' learning behaviour. Empirical evidence for the relevance of attitudes also has been found for specific subjects - for instance, research indicates that problems observed in statistics courses are not due to educator- or knowledge-related insufficiencies but rather to attitudinal factors (Baloğlu, 2003; Gal \&Ginsburg, 1994). Not surprisingly, the relevance of attitude in academic behaviours has been confirmed by several studies. Ajzen and Madden, for example, showed back in 1986 that attitude has a relevant influence on the intention to attend class. Also, positive effects of attitudes on the studying intention in general have been found (Leone et al., 1999). On the other hand, some studies obtained rather unclear results for attitudinal effects. As already mentioned, Lay and Burns (1991) investigated an extended model of TPB in the studying for exams context. In their study, attitude influenced intention under specific conditions only. Furthermore, Manstead and Van Eekelen (1998), when examining academic achievement intentions, even found negative influences of attitudes.

Looking at the preparing for exams-behaviour through a TPB-lens let it appear to be rather ambiguous. When a student has to sit an exam at the end of the course, this is compulsory - the student has to do the test, and even the most intelligent students have to prepare. So it is unclear what room is left for his personal evaluations of preparing. On the other hand, while the course-work itself will be regulated by the course instructor at least to a certain degree, the amount of time invested in preparing for the exam is very much up to student himself. Hence, what he is thinking about the preparation activity could play an important role indeed. For instance, whether or not he likes preparing or whether or not he likes the subject at all is very likely to influence his motivation to prepare. Hence, a positive effect of a positive evaluation can be assumed. Therefore, H1a is as follows:

H1a: Students' attitudes towards preparing for exams have a significant, positive influence on the goal intention to properly study for exams. 
According to Ajzen (1991), subjective norm can be understood as "perceived social pressure to perform" (Ajzen, 1991, p. 188) the behaviour in question. Similarly to attitudes, a higher value of social pressure seems to lead to higher levels in goal intention. While subjective norms represent an integral part of TPB, several meta analyses have indicated that it seems to be a rather weak predictor (Armitage\&Conner, 2001). With respect to the academic context this paper is focusing on, it is straightforward to think about parents' expectations to which students are probably willing to correspond. Actually, there is a consensus that what parents expect their children to do has a considerable effect on their behaviour. This is also true for academic performance: "It is clear that high achieving children tend to come from families which have high expectations for them, and who consequently are likely to 'set standards' and to make greater demands at an earlier age" (Boocock, 1972, p. 60). Vollmer concluded in 1986 that "many empirical studies have found positive linear relationships between expectancy and subsequent academic achievement" (Vollmer, 1986, p. 15). Interestingly, this connection seems to be stable over varying social, economic, and ethnic backgrounds (Henderson, 1988). However, other studies indicate that with respect to academic achievement, cultural influences seem to matter (Chen \&Han, 1998). Wentzel (2005) argued that so-called social expectations by peers in general add to the set of goals students are pursuing during their academic career. Moreover, studies showed that students have social goals such as gaining social or family approval (Urdan\&Maehr, 1995). These social goals are at least to a certain extent associated with academic outcome (Hicks et al., 1995). Theory of Planned Behaviour studies in academic contexts, however, did not always find clear results with respect to the impact of social norm. For instance, the study by Ajzen and Madden (1986) reported only for one out of two experiments significant effects. In contrast, Leone and his colleagues (1999) obtained significant, medium-level influences for subjective norm on the intention to study. Similarly, Prentice et al. (2009) got highly significant medium-level effects when examining academic performance in statistics.

Despite these rather unclear findings, it is straightforward to argue that students try at least to a certain extent to correspond to expectations of others. This could be the family - here, we can assume particularly strong relationships as parents often at least partially fund students' expenses. In turn, the family probably expects some sort of trade-off; that is the student to make effort in order to deliver a good performance. Social pressure can also come from teachers or other students. Teachers very often clearly say what work is necessary in order to pass the exams. Student peers may exert influence even in two different ways: first, students observe how much time other students invest when preparing for exams. Second, they very likely listen to what their fellow students communicate with respect to what social pressures they feel. Hence, a positive effect of social norm on goal intention can be assumed. It is proposed that:

H1b:There is a positive relationship between social norm and students' goal intention to properly prepare for exams.

Perceived Behaviour Control is according to Ajzen (1991, p. 188) the "perceived ease or difficulty of performing the behaviour and it is assumed to reflect past experience as well as anticipated impediments and obstacles". The higher $\mathrm{PBC}$, the larger an individual's motivation to really perform the corresponding behaviour. Please note that $\mathrm{PBC}$ is a relevant construct for behaviours where volitional control is at least partially absent. Beyond doubt, studying and also preparing for exams can be subsumed to this class of behaviours. This is among other reasons due to its complex character (Leone et al., 1999). Students have to develop schedules, have to identify relevant knowledge, have to deal with stress which arises from the fact that several examinations have to be passed, etc. Students also face several other challenges. Inadequate textbooks (Sutman, 1992) and inadequate reading abilities (Pressley et al., 1997) represent a rather basic hindrance. Furthermore, students may have difficulties with note taking and recognizing examination demands. Pressley and his colleagues (1997) described such problems as inadequate teaching as the teacher should make sure that the students have gathered and understood the relevant information given to them in course. These researchers also described another major problem in the preparing for exams context: inadequate information processing abilities such as reading deficiencies or lack of background knowledge. From this brief overview it can be seen that there exists a wide range of internal and external hindrances. The former include for example lack of intelligence, while the necessity to spend a considerable part of time to earn the living belongs to the latter. Not surprisingly, academic achievement has been described as a context where internal and external control factors play important roles (Manstead\&Van Eekelen, 1998). According to Pressley et al. (1997) an important element of an appropriate preparation process is proper preparation ability. This apparently perfectly fits $\mathrm{PBC}$, as several researchers have suggested that PBC, conceived as confidence in one's ability, is a very important predictor of goal intentions (Armitage\&Conner, 1997; Guthrie, \&Sparks, 1997). Please note that this conception makes PBC somewhat similar to Bandura's (1982) self-efficacy construct. Empirical evidence for the relevance of $\mathrm{PBC}$-effects in academic settings have been found by several authors. One of the first studies dealing with $\mathrm{PBC}$ was conducted by Ajzen himself in order to test the relevance of the construct with respect to class attendance (Ajzen\&Madden, 1986). Furthermore, the study by Leone and his colleagues (1999) did find moderately strong positive effects of PBC. Similar results have been obtained by Prentice et al. (2009) who found that $\mathrm{PBC}$ was by far the strongest influence on the intention to properly prepare for statistics exams. However, the picture is 
not as clear as it appears to be. Lay and Burns (1991) who applied a TPB model extended by procrastination and other elements did not find consistent relationships between PBC and the intention to study for exams.

Nevertheless, it seems to be clear that students' perception of their ability to prepare for exams is at least to a certain extent a relevant influence. For instance, if a student thinks that he/she has all the texts relevant for exams, his/her motivation to prepare should be higher as for a student who feels that he/she is missing relevant data. Also, goal intention to study for exams is likely to be higher if the student is convinced that the time available for preparing is sufficient. Thus, H1c can be put as follows:

H1c: A high level of perceived behavioural control positively influences the goal intention to properly prepare for exams.

Several studies demonstrated that goal intentions seem to have an important influence on educational outcomes (Graham et al., 1995; Morgan, 1985). However, empirical results indicate, that large goal intentionsare not necessarily linked to behaviour. For instance, Webb et al. (2007) examined class attendance, and their findings put into perspective the effects of having a high level of motivation: "As expected, students were highly motivated to attend class; however, attendance rates were low" (Webb et al., p. 323). According to the authors, an implementation intention intervention proved to be successful as it raised class attendance considerably. This finding underlines the contention by Gollwitzer and Brandstätter (1997) that implementation intentions are formed in the service of goal intentions. Furthermore, it indicates that by no means the former are developed automatically as soon as the latter are available. Nevertheless, implementation intentions definitely require the existence of goals which an individual tries to reach (Sheeran et al., 2005). Furthermore, the study by Sheeran and colleagues (2005) indicated, that implementation intentions are effective only if there are large goal intentions. This is in line with Gollwitzer and Brandstätter (1997) who argued that people are likely to show a greater readiness to develop implementation intentions in case the superordinate goal intentions are strong. Moreover, Orbell and his colleagues (1997) make the case that goal intentions determine the strength of implementation intention effects. In their study on breast self-examination, more persons with strong goal intentions performed the behaviour than persons holding implementation intentions.

Such a relationship also can be assumed for the preparing for exams context. As soon as a student has decided to participate in a certain exam, he/she very likely also has the goal to prepare himself/herself at least on a cursory level. As the date of examination is given externally by the university or the teacher, the student very likely is aware of this deadline, that is he/her knows that his/her preparation activities - regardless their intensity - have to be accomplished by the date the examination will be carried out. This would imply that forming the goal to study for exams also generates to a certain extent a plan for studying, i.e. in this particular context implementation intentions probably to a certain extent are formed naturally (Orbell\&Sheeran, 2000). This in turn would mean that the larger the student's motivation to prepare for exams, the more likely he/she is to also develop concrete plans for studying and the more likely these plans are to be implemented. As implementation intentions link specific situational contexts to behavioural enactment, the above described relationship implies a two-way-automaticity: first, goal intentions initiate natural formation of implementation intentions; second, when the student recognizes the specified situation, behaviour is started automatically. Hence, for $\mathrm{H} 2$ follows:

H2: There is a positive correlation between goal intention to properly prepare for exams and corresponding implementation intentions.

Showing certain behaviour depends on numerous causes (Ajzen, 1988). This is why it is not surprising that neither goal intention nor behaviour can be completely explained by TPB's main variables. Rather, it can be assumed that additional variables such as past behaviour also play a role (Leone et al., 1999). Past behaviour has been suggested to be captured by the so-called background factors (Ajzen, 1991) and especially by PBC (Ajzen\&Madden, 1986). However, several researchers have argued and empirically underlined that past behaviour might have direct effects on future behaviour (Oulette\&Wood, 1998). Also, influences of past behaviour on goal intentions have been reported. For instance, Rhodes and Courneya (2003, p. 65) found that "past behaviour had the largest effect on current intentions along with effects from affective attitude and PBC". Furthermore, past behaviour seems to also exert indirect influences. Kidwell and Jewell (2008) make the case that past behaviour obviously moderates the influence "...of attitude and internal and external control on intention" (Kidwel\&Jewell, 2008, p. 1162). Hence, past behaviour obviously can influence TPB constructs and hence the deliberative mental process of decision making.

Past behaviour also seems to trigger future behaviour automatically in the form of habits. Aarts et al. (1998) argue, that "...because of frequent performance in similar situations in the past, these mental representations and the resulting action can be automatically activated by environmental cues" (Aarts et al., 1998, p. 1359). This is somewhat similar to implementation intentions as they imply that goal implementation is automatically started as soon as a specified situation is encountered (Gollwitzer, 1993). However, habits may directly lead to action; they only to a limited extent require 
conscious reasoning. Implementation intentions are somewhat related to past behaviour. Orbell et al. (1997) have argued that they can reduce the effect of past on future behaviour. This indicates that at least to certain extent past behaviour influences the development of implementation plans. Furthermore, for the domain of academic performance, Manstead and Van Eekelen (1998) showed that past performance is the best predictor of academic achievement. As for this behaviour no full automaticity seems to exist, implementation intentions are the immediate antecedent to behaviour. This indicates that there seems to exist a link between past behaviour and implementation intentions. In fact, it is straightforward to argue that having performed a specific behaviour in the past has given the individual relevant knowledge about when, where, and how one might enact intentions (Rise et al., 2003). This idea is in particular relevant for the preparing for exams context. Having successfully met challenges gives the student concrete guidelines what steps are necessary in similar situations. Such experiences facilitate the generation of for instance learning plans and thus the creation of implementation intentions. In order to investigate this aspect, $\mathrm{H} 3$ is defined as follows:

H3: There is a positive relationship between students' earlier experience with preparing for exams and the development of implementation intentions.

As already mentioned, implementation intentions can support behavioural enactment. Performing the behaviour is related to a pre-specified situation. As soon as the latter is given, implementation starts: "I intend to do y when situation z is encountered" (Gollwitzer\&Brandstätter, 1997, p. 187). According to Gollwitzer (1993), implementation intentions represent a powerful tool as they are conceived as a self-regulatory strategy. However, the effects of implementation intentions in the context of TPB can be weakened by other constructs. Gollwitzer and Sheeran (2009) outlined that "when one doubts the appropriateness of forming implementation intentions, no implementation intention effects can be expected" (Gollwitzer\&Sheeran, 2009, p. 603). This may also be the case when strong habits are given - the automaticity associated with them may override the automatic effect of implementation intentions (Verplanken\&Faes, 1999). Furthermore, personality influences may interfere with implementation intentions. It has been shown that socially-prescribed perfectionism (Powers et al., 2005) can lead to lower goal attainment. Also, for students with a rather high level of conscientiousness, the effects of implementation intentions are weaker as for to their low-conscious fellows.

Procrastination also may have negative effects on intentions. While several authors could not find such effects (Dewitte\&Lens 2000), Sirois (2004) argued that procrastinators indeed could weaken intentions to show certainbehaviour. Furthermore, van Eerde (2000) made the case that procrastination can be conceived as a breakdown of the implementation of an intention to act; here, procrastination can lead to the avoidance of intention. While implementation intentions generally are regarded as a means to overcome procrastination (Owens et al., 2008), there might also exist negative effects in the opposite direction. Howell and his colleagues (2006) were among the first who investigated the interrelationships between self-reported procrastination, implementation intentions, say-do correspondence, and perceived academic control. They found empirical evidence for a negative correlation of procrastination - as measured by the 16-item Procrastination Scale (Tuckman, 1991) - and implementation intentions. Although their results are not unequivocal, they indicate that trait procrastination might - as some personality traits did affect the development of implementation intentions. In his meta-analysis, Van Eerde (2003) stated that there is a negative relationship between procrastination and task preparation; furthermore, there seem to exist moderated negative relationships between procrastination and course grade. Hence, if procrastination hinders students' preparation and leads to bad results, procrastination could affect the development of implementation intentions. This would be particularly relevant in the studying for exams context, as implementation intentions might here be developed automatically due to the fixed deadline represented by the examination date. To clarify this assumption, $\mathrm{H} 4$ is defined as follows:

H4: There is a negative correlation between students' procrastination and the reported level of implementation intentions.

\section{Methodology}

In order to investigate the above mentioned aspects, a structural equation modelling approach will be applied, using AMOS 17.0. As core literature for this chapter the guideline by Weiber and Mühlhaus (2010) was used. Based on their recommendations, chapter 4 was subdivided in the following subchapters: 4.1. Modelling, 4.2.Conceptualization, 4.3. Operationalization, 4.4 Assessment of psychometric properties (reliability/validity), 4.5.Estimation of the model, 4.6.Model evaluation, (Weiber\&Mühlhaus, 2010, pp. 73-74). The outstanding "discussion of the results" according to the authors is part of chapter 5 (Weiber\&Mühlhaus, 2010, p. 74).

Empirical basis of the research are the row data out of a survey at the Faculty of Engineering of the Albstadt-Sigmaringen University / Germany dated from 2010 (Sommer, 2010). In total, 1.149 students of the Faculty of Engineering have been invited to answer the questionnaire in a written form. Participation was completely voluntary. 
No financial or other incentive was offered. Before the survey was started, a pre-test including 25 students selected by choice has been conducted. Data were gathered end 2009 / beginning 2010, that is right in between start of the semester and exams. The questionnaire is based on 35 items and is divided in three parts. The first one was used to figure out general information (for example age, education, experience), the second is based on items of the TPB and the last one used the procrastination scale of Aitken (1982). For further details see subchapter 4.2. or the annex. 239 questionnaires were filled in, 218 could be included into the empirical analysis. Students generally were male (about $80 \%$ ), average age equals 22.5 years. Most of them - $63.8 \%$ - have a general university entrance certificate, which is equal to A levels in UK (Sommer, 2010).

\subsection{Modelling}

The latent variable will be determined on the basis of a reflective measurement model, which in turn will make use of the maximum-likelihood method (Weiber\&Mühlhaus, 2010, pp. 75-77). The core of the research model is TPB (Ajzen\&Fishbein, 1975), where intentions are segregated into goal and implementation intentions (Heckhausen\&Gollwitzer, 1987). Further elements integrated are procrastination (Aitken, 1982) and past behaviour /experience. An additional option is Kuhl's concept of action vs. state orientation (Kuhl, 1994). The model could be described as follows (excluding the concept of Kuhl):

--- place figure 3 here ---

Figure 3 - Research Model

Source: Own Illustration

\subsection{Conceptualization}

Main basis for conceptualization of the latent variable are the respective theories and item batteries successfully used in earlier studies. Some items had to be modified or developed (Weiber\&Mühlhaus, 2010, pp. 79-80). Some measurements used single items, others relied on multi-item batteries; here, changes indicated by the pre-test were implemented:

Table 1 - Constructs and measurement approach

Source: Own Illustration

$$
\text { --- place table } 1 \text { here --- }
$$

* - items actually used after pre-test as compared to original number of items

** - Ranging from 1 (Totally disagree) to 5 (Totally agree)

*** - State vs. action orientation was included into the final analysis

\subsection{Operationalization}

The operationalization of the constructs is based on the guideline of Weiber and Mühlhaus (2010). Most of them are defined by former research activities. The above listed constructs were measured by the following included items. For each item the 5-point Likert scale was used. Items, which were excluded by the pre-test, are not described below.

- The following items grasped goal implementation:

○ I intend to prepare appropriately for the examinations.(Gollwitzer et al., 1993) - Item "I 1"

- Implementation intentions were measured as follows:

- I have a detailed plan how, when and what preparation is necessary for the exams. (Hrisos et al., 2008; Gollwitzer, 2003) - Item "I 2"

- I know exactly what circumstances might make modifications of the preparation plan necessary and how possible delays can be remedied. (Hrisos et al., 2008; Gollwitzer, 2003) - Item "I 3"

o For the current semester, it is fair to say that my preparation activities have begun in November 2009 Item "I 17"

○ For the current semester, it is fair to say that my plans for preparation for examinations have been accomplished by mid November 2009 - Item "I 18"

- Attitudes were measured as follows:

$\circ$ "Do you think that the total amount of time invested for preparation in order to get a good grade is useful?" (Sheeran et al., 2005) - Item "I 6" 
○ "How likely is it that the hours invested in preparation of the exams will be boring?" (Sheeran et al., 2005) - Item "I 7"

- Social norms were captured by the following items:

○ "Most of the people who are important to me expect me to properly prepare for examinations" (Rhodes et al., 2006; Gollwitzer et al., 2005). - Item "I 8"

○ "Most of my student colleagues would say that the time I invest in preparation for the exams will be sufficient" (Rhodes et al., 2006; Gollwitzer et al., 2005) - Item "I 10"

- Perceived Behaviour Control was measured using the following items:

o I'd like to prepare myself as thoroughly as possible for the exams; however, I am not sure whether or not I am able to do so. (Hrisos et al., 2008) - Item "I 11"

○ Whether or not my preparation for the exams is proper only depends on me.(Hrisos et al., 2008) - Item "I 12"

- Experience was measured by the following item:

○ Were the contents of the relevant university course known by school or your former job? - Item "I 15"

- The instrument presented by Aitken (1982) was used to capture Procrastination. The author used 19 items. The elements have been aggregated to an Index "I 16"

The data gathered were tested for outliers and missing values. The test for normal distribution yielded critical rations (CR) between 0.110 and 5.071. Comparing this to recommended threshold values of 2.57 and 1.96, respectively (Weiber\&Mühlhaus, 2009, pp. 147 et seqq.; Browne, 1982, p. 100), five items had to be excluded due to violations.

\subsection{Assessment of psychometric properties (Reliability/Validity)}

According to Weiber and Mühlhaus (2010) follows the assessment of reliability and validity (Weiber\&Mühlhaus, 2010, pp. 103-140). In line with the authors the assessment should be used for the current research paper. The statistical software that is used is AMOS 17.

Reliability: The test for uni-dimensionality while simultaneously considering all constructs via exploratory factor analysis, yielded a (Kaiser-Meyer-Olkin) KMO-value of 0.617 (Kaiser \&Rice, 1974, pp. 111 as cited in Weiber\&Mühlhaus, 2009,pp. 107 et seqq.). When the Barlett-test was applied, a Chi-Square value of 511.01 was obtained at 78 degrees of freedom at $p<.000$. Measures of sampling adequacy are between 0.556 and 0.776 (except for one item). This means that the threshold value of 0.5 is exceeded in all cases (Weiber\&Mühlhaus, 2009, p. 107). As the violation was on a marginal level only, the corresponding item was not excluded. All constructs comprised 31 items which equal an extraction sum of factor loading of 51.959. In other words, about $52 \%$ of variance of input variables can be explained. Summarizing these figures, the structure of variables assumed prior to the analysis is strongly supported.

The reliability analysis using confirmatory factor analysis yielded values between 0.326 and 0.726 for indicator reliability. With the exception of two items, the threshold value of 0.4 is not violated (Bagozzi\&Baumgartner, 1994, p. 402 as cited in Weiber\&Mühlhaus, 2009, p. 127). When computing factor reliability, values between 0.4 and 0.8 were obtained for all constructs. This means that all but one constructs reached the threshold value of 0.6 (Bagozzi\&Yin, 1988, p. 82 as cited in Weiber\&Mühlhaus, 2009,p. 127). If the less stringent threshold values suggested by Balderjahn (1986, p. 118 as cited in Weiber\&Mühlhaus, 2009, p. 127) - i.e. 0.3 to 0.5 - are accepted, all constructs can be included. For the average value of extracted variance, values between 0.35 and 0.69 were computed. With the exception of one construct, the threshold value of 0.5 (Formell\&Larcker, 1981, p. 46 as cited in Weiber\&Mühlhaus, 2009, p. 127) was met. Hence, CFA also confirms construct reliability.

Due to the fact that violations in EFA and CFA were only marginal, no constructs were excluded.

Validity: The study at hand mainly used items successfully applied by other researchers. Content validity thus can be expected. Construct validity also can be assumed, as all average values of extracted variance are larger than 0.5 (Formell\&Larcker, 1981, p. 46 as cited in Weiber\&Mühlhaus, 2009,p. 137).

\subsection{Estimation of the model}

Based on the constructs described above, the path diagram is built using the variables presented below:

Table 2 - Variables included

$$
\text { --- place table } 2 \text { here --- }
$$


This structure is based on the following assumptions:

- Variables V1 to V4 have a purely explicative character and thus are exogenous

- Variables V6 to V8 are influenced by other constructs and thus are endogenous

- Items I1, I2, I16, I15, I12, I8, and I6 represent reference indicators or fixed parameters, respectively. They are fixed using a path coefficient of 1 . A regression coefficient equalling 1 has been defined for the relationship between residual terms and constructs. The other parameters are not fixed.

- The latent variables were assigned metrics of reference indicators.

These measures lead to the following path diagram:

$$
\text { --- place figure } 4 \text { here --- }
$$

Figure 4 - Path diagram -research model (including hypotheses H1 - H4)

\section{Source: Own illustration based on AMOS 17}

The test for identifiability showed 91 empirical variances co-variances were opposed by 45 parameters which had to be estimated. Degrees of freedom therefore is 46 , Chi-Square is 101.06 at $p<.000$. All relevant matrices were positive, thus identifiability can be assumed.

\subsection{Model evaluation}

Furthermore, tests for plausibility were conducted. No Heywood cases were found (Weiber\&Mühlhaus 2009, p. 159). Inference-oriented quality criteria yielded threshold values of 101.06 at 46 degrees of freedom. This means, that the computed variables fit the empirically gathered data moderately well. When applying the RMSEA-method by Brown and Crudeck, a value of 0.07 was obtained. This does not exceed the threshold value of 0.08 ; hence an acceptable model fit can be assumed (Weiber\&Mühlhaus, 2009, p. 162).

Also, descriptive quality criteria suggest an acceptable model (Weiber\&Mühlhaus, 2009, p. 162):

Table 3 - Descriptive quality criteria

$$
\text { --- place table } 3 \text { here --- }
$$

Incremental fitting indices obtained when comparing default and independence model confirmed the assumptions presented above (Weiber\&Mühlhaus, 2009, pp. 164-171):

Table 4 - Fitness indices

$$
\text { --- place table } 4 \text { here --- }
$$

\section{Results}

In chapter 5 follows the "discussion of the results" according to Weiber and Mühlhaus (2010) (Weiber\&Mühlhaus, 2010, pp. 73 - 74).

\subsection{Plausibility Check}

The quality indicators presented above allow for test of plausibility and parameter estimation based on the critical ratio (CR) and probability of errors (p) for the following six hypotheses (Weiber\&Mühlhaus, 2009, pp. 180 et seqq.):

Table 5 - Results for hypotheses

--- place table 5 here ---

Taking into account the CR-threshold value of 1.96 (Weiber\&Mühlhaus, 2009, p.180) as well as the levels of significance, hypotheses 2, 3, 4, and 6 are supported. Hypothesis 1 is slightly violated, hypothesis 5 moderately violated. Both hypotheses are not excluded from the model, but are analysed separately. Squared multiple correlations (SMC) for latent endogenous variables / constructs goal and implementation intention equal 0.85 and 0.753 , respectively. Hence, they can be considered substantial (Chin, 1998, p. 323 as cited in Weiber\&Mühlhaus, 2009, p. 181).

The analysis of causal effects based on figure 2 - path diagram containing standardized parameters - for all hypotheses confirms the assumed direction of effects. As expected, there is only one negative influence on implementation intention, i.e. procrastination. All other constructs exert positive influences.

Based on the recommendation by Chin (1998a, p. 8 as cited in Weiber\&Mühlhaus, 2009, p. 181 and 185), only regression coefficients having an absolute value larger than 0.2 are substantial. All relationships presented in figure 2 therefore are substantial. Measurement errors with respect to endogenous variables equal values between 0.15 (e-18) and 
0.59 (e-2). More specifically, e- 18 is associated with $85 \%$ of unexplained variance of implementation intentions, which is rather high. Contrariwise, $41 \%$ of unexplained variance is rather moderate (e-2). For goal intention, e-1 had a proportion of $43 \%$ of variance not explained, which also is rather moderate.

Squared multiple correlations (SMC) is a measure similar to $\mathrm{R}^{2}$ in multiple linear regression. For goal intention, the analysis yielded a value of $85 \%$. This means that about $85 \%$ of variance in goal intention can be explained by TPB main constructs attitudes, social norm, and PBC. Interestingly, the strongest causal effect is exerted by social norms, followed by PBC. Attitudes have a rather weak effect. As for the second endogenous construct, to be precise implementation intentions, the proportion of variance explained by goal intention, experience, and procrastination equals $75 \%$. Experience had a strong effect, second only to goal intention which had the strongest direct influence. A considerable negative effect is exerted by procrastination. Indirect effects are gained by multiplying the corresponding partial effects.

$$
\text { --- place figure } 5 \text { here --- }
$$

Figure 5 - Path diagram including standardized coefficients (including hypotheses H1 - H4)

\section{Source: Own illustration based on AMOS 17}

An overview of the causal effects and explained variances could be seen in the following figure. Approx. $85 \%$ of the variance of the endogenous variable "Goal Intention" as well as $75 \%$ of the endogenous variable "Implementation Intention" are explained.

--- place figure 6 here ---

Figure 6 - Research Model including causal effects

Source: Own Illustration

\subsection{Discussion of results}

Based on the results from the statistical analysis presented in section 5.1, we will now discuss the main findings for each hypothesis.

H1a: Students' attitudes towards preparing for exams have a significant, positive influence on the goal intention to properly study for exams.

About $85 \%$ of variance in goal intention have been explained by the model presented in section 5.1. As assumed when developing the hypotheses, attitudes have a positive effect on the formation of goal intention. However, this effect is moderately strong only. As compared to the two other main constructs of TPB, it even shows the weakest effect. Hence, attitudes play a - yet rather small - role when it comes to preparing for exams. This basically supports H1a and puts the results by Lay and Burns (1991) to a certain extent into perspective: here, under each circumstance, attitudes seem to have a positive effect. This findings further underline that the negative effects of attitudes found by Manstead and van Eekelen (1998) seem to be due to methodological issues. From a practical point of view, the findings underline that even for behaviours which are to a certain extent dominated by externally imposed conditions - the date of the examination as well as the knowledge relevant for the test are given by the course instructor - attitudes play a role when the decision about preparing for the exam is about to be made. Furthermore, the relevance of the TPB-construct attitudes can be confirmed even for such a specified context and thus represent a starting point for interventions. Then again, the suggestion by Ajzen (1991) that the relative importance of each construct varies over different forms of behaviour is confirmed, too. Basically, attitudes have to be considered in academic contexts; nevertheless, they might be outperformed by other TPB elements, as the results for H1b show.

H1b: There is a positive relationship between social norm and students' goal intention to properly prepare for exams.

Armitage and Conner (2001) suggested in their meta-analysis, that subjective norm is a rather weak predictor in many TPB applications. This makes the findings of the study at hand really interesting as it turned out that the strongest influence on goal intention is exerted by subjective norm. Other studies dealing with academic scenarios also found significant effects of norm (cf. Leone et al., 1999; Prentice et al., 2009). In the current study, however, subjective norm clearly dominates all other influences. It has been suggested by several authors, that expectations of third parties may play a role when students develop intentions for certain academic behaviours such as attending for class or doing homework (Chen \&Han, 1998; Wentzel, 2005). As early as 1986 Vollmer argued that there exists a positive relationship between expectancy and academic success. In the context of the paper at hand, such expectations apparently are at least partially included into the subjective norm construct which in turn lead to strong goal intentions to properly prepare for exams. Hence, it is not personal evaluations by the individual but rather expectations from others towards the individual which increase its motivation to prepare for exams. This is an important starting point for intervention strategies. Such 
expectations of course may not only stem from parents or family members. For a student, it could be much more important what his peers think should be appropriate. Furthermore, an even more important influence might not be based on what the peers probably think but what they actually do. While the former is called injunctive, the latter refers to a conceptualization of subjective norm as so-called descriptive norm. Future research should clarify which type is more relevant when it comes to preparing for exams.

H1c: A high level of perceived behavioural control positively influences the goal intention to properly prepare for exams.

As for the third main influence of TPB, i.e. PBC, also a considerable effect has been obtained. As preparing for exams indeed is a rather complex behaviour, it is anything but surprising that elements of perceived control play a role here. Many aspects - both internally and externally attributed - form a framework in which the student has to study for exams. As an example, inadequate teaching or inadequate reading skills can be mentioned. The findings of the current study confirm earlier papers dealing with similar academic contexts which also find relevant influences exerted by PBC (cf. Ajzen\&Madden, 1986; Leone et al., 1999; Prentice et al., 2009). Interestingly, these results once again put in question the study by Lay and Burns (1991). Their approach was to a certain extent similar to the one followed in this paper as it also included procrastination into the research model. Furthermore, they also analysed studying for exams. Still, both authors did not find consistent influences of PBC. What makes the finding of the paper at hand even more interesting is that past behaviour has been explicitly modelled, too. $\mathrm{PBC}$ is said to capture a lot of elements represented by experience or past behaviour, respectively. Nevertheless, $\mathrm{PBC}$ turned out to be the second-strongest influence on goal intention. This underlines that in complex settings a construct covering perceptions of control or ability, respectively, is necessary and that PBC alone in an academic setting cannot fully absorb past behaviour effects.

H2: There is a positive correlation between goal intention to properly prepare for exams and corresponding implementation intentions.

It is clear that examination has to be done and that the examination date is externally set. This would imply that a student has to start with his/her preparations for example at the latest two days before the exams. In turn, this would only be the case if the student had made the decision to prepare himself/herself properly - in this case, he/she would have a corresponding goal intention. The structural equation modelling-approach in section 4showed that there are several relevant influences on implementation intentions. The largest among them is goal intention. This finding supports the suggestion by Orbell and his colleagues (1997) that strength of goal intentions shows impact on implementation intentions. Furthermore, the study at hand also supports Sheeran et al. (2005) who suggested that the rate of goal attainment based on implementation intentions is affected by strength and activation of superordinate goal intentions. These results also underline the possibility, that with respect to the preparing for exams behaviour, implementation intentions may develop naturally in concert with goal intentions. However, this might only be the case when goal intentions are large. This aspect should be clarified in the course of future studies.

H3: There is a positive relationship between students' earlier experience with preparing for exams and the development of implementation intentions.

Several authors have suggested that past behaviour in TPB can have the form of automatic behavioural responses to certain situational contexts, i.e. habits (Bamberg, 1996; Aarts\&Dijksterhuis, 2000; Sheeran, 2002). It has been found in section 5.1 that the second largest effect on implementation intentions stems from experience. This indicates that past behaviour does not only lead to (semi-) automatic behavioural responses but also to intentional reactions. More specifically, the empirical results support the contention by Rise and his colleagues (2003), that knowledge gathered in the course of past behaviour on when, where and how intentions might be carried out influences the formation of implementation intentions. As already mentioned above, the preparing for exams context may be somewhat specific in that it is likely to support the natural development of implementation intentions in concert with strong goal intentions. It is straightforward to argue that this process of natural development is also influenced by what has been learned in the past at the occasion of similar behaviours. A student in the third year very likely has learnt what is necessary and what is rather distracting when an efficient and effective preparation for exams should be done. From this point of view it is everything but surprising that experience has a considerable positive effect on implementation intentions. Nevertheless, how exactly such experiential knowledge influences the formation process has to be clarified in future studies.

H4: There is a negative correlation between students' procrastination and the reported level of implementation intentions.

Several studies in different fields argued that implementation intentions are an effective means to overcome the negative consequences of procrastination (cf. Owens et al., 2008; Van Hooft et al., 2005). As procrastinators very often show some sort of dilatory behaviour, it is clear that deliberative planning may help them perform better. But what does this 
mean with respect to the above-mentioned natural evolution of implementation intentions? When an individual shows dilatory tendencies when to start a behaviour, this might also be the case when he/she prepares to perform the behaviour in question. This consideration is supported by another finding from section 5.1. Procrastination had a considerably negative effect on implementation intentions. This clearly supports the suggestion by Howell and his colleagues (2006) who found a negative correlation between procrastination and implementation intentions. Thus, not only the goal intention formation process is affected by procrastination (Van Eerde 2000; Sirois 2004), but also the development of implementation intentions. In contrast, Van Hooft et al. (2005) did not find a relevant effect of procrastination on the implementation intention-behaviour relationship. As the authors suggest, this might be due to methodological issues and the fact that their study only investigated the procrastination-behaviour relationship. Whether or not procrastination already interfered with the development of implementation intentions remains unclear. From a practical point of view, this aspect is of crucial importance. If implementation intentions really help perform, but are on the other hand affected by trait procrastination, intervention measures clearly should take care of "protecting" both implementation intentions as well as their development. This paper did not analyse the effect of implementation intentions on behaviour. How the effectiveness of these intentions on behavioural enactment might be interfered has to be clarified in future studies.

\section{Conclusion}

While several papers in the past dealt with challenges students have to face when preparing for exams (cf. Pressley et al., 1997 for an overview), only a few investigated the cognitive process preceding the concrete preparation activities, papers such as the one by Lay and Burns (1991) or Prentice et al. (2009) being rather the exception than the rule. A cognitive perspective on the topic allows for developing effective interventional measures which could help students improve their academic success. Following a post-positivist approach, the paper at hand used an extended model of the Theory of Planned Behaviour (TPB) in order to examine which role - besides the theory's main constructs - experience, procrastination, and implementation intentions play. Based on a sample of 218 undergraduate students of a German university, structural equation modelling was used.

The main findings are as follows:

- Among the main elements of TPB, the largest influence on goal intention was exerted by subjective norm. This result may be due to the academic achievement context this paper is dealing with; generally, norm appears to be a rather weak predictor in TPB settings (Armitage\&Conner, 2001). While perceived behavioural control also had a considerable effect, attitudes exerted an only weak influence on goal intention. This may be due to the fact that the rather rigid context - an exam has to be passed, the date of examination is set externally - leaves not much room for personal evaluations.

- There is a considerable positive effect of goal intention on implementation intentions. As the latter were naturally formed in this study - explicitly no intervention took place - this is an interesting finding. It supports the idea, that development and effect of implementation intentions profit from strong goal intentions (Orbell et al., 1997; Sheeran et al., 2005). This could be due to a natural development of implementation intentions, which seems to work in concert with strong goal intentions. Here, also context seems to play a role. As the examination has to be done and its date is given, the student very likely is aware of the fact that there is a deadline for beginning appropriate preparation measures.

- A very strong positive effect on implementation intentions has been found for experience, as well. While it has been argued by several researchers that past behaviour may lead to the formation of habits (Aarts\&Dijksterhuis, 2000 ) - i.e. an automatized behavioural response in the certain situation - such a short-cut may also exist for the development of implementation intentions. For rather simple behaviours such as recycling or exercising, it can be assumed that the deliberative part of the cognitive process preceding action is rather low. However, preparing for exams is a more complex behaviour, it requires students to identify relevant knowledge, reread important texts, make a schedule, and so on. Nevertheless, the automatized element here rather seems to show effects on the development of an implementation plan. Having prepared for several other examinations provides the student with specific experience or knowledge which facilitates the planning of similar activities.

- Procrastination is said to negatively influence behaviour. For instance, procrastinating students seem to start later with preparational measures. The paper at hand found evidence for a negative influence of procrastination on implementation intentions - the cognitive element next to behaviour -, as well. This supports the idea that not only goal intentions are affected by procrastination (Sirois, 2004) but also the natural development of implementation intentions. As making a plan actually represents a behaviour itself, it is logical to argue that even such a rather effortless activity is likely to be affected by procrastination. 
From the findings presented above, several practical implications can be drawn:

- Subjective norm has a strong effect on the formation of goal intentions. However, attitudinal aspects are rather weak influences. Hence, the goal to prepare properly for the exam could be strengthened by interventions influencing the personal evaluation of this activity. Here, purely information-oriented measures can be used for example illustrating best-practice examples showing how effective good preparations are. But also affective aspects can be addressed, for example by reducing anxiety towards the subject itself (Prentice et al., 2009). This can be done by initiating learning groups which are coached by higher semester students who have already successfully passed the examination in question.

- It has been argued by several authors, that implementation intentions help perform a behaviour. For the context examined in the paper at hand, empirical evidence has been found, that implementation intentions seem to evolve to a certain extent naturally, probably in concert with strong goal intentions. Hence, students should be supported in developing such goal intentions. Second, the process of natural formation of implementation intentions should be supported as well. This can be done by presenting action plans which proved to be useful for other students. Also, a course "how to prepare appropriately" for exams should be offered in the first semester. Here, students gain their first experiences with studying for exams - this aspect is particularly relevant as experience also strengthens implementation intentions.

- Perceived Behavioural Control also has a considerable effect on the formation of goal intentions. Course instructors should make sure that the students have everything at hand that is necessary for preparing properly. First of all, this implies good teaching. Second, all texts and materials necessary for examination should be easily available. Also, by using e-learning elements, students can repeat the relevant topics whenever they want; furthermore, e-learning platforms represent an efficient means to provide 24-7 access to course materials and allow students to communicate online.

- Procrastination is a major problem, as between $50 \%$ and $95 \%$ of college students are at least temporarily engaged in procrastination (Day, Mensink, \&O'Sullivan, 2000). This paper found evidence for negative effects not only on behaviour but also on implementation intentions. Hence, the process of developing both types of intentions should be supported as described above. At the same, it should be protected against interfering influences. This can be done by teaching the students to use reminder notes, breaking complex goals into smaller ones (Ferrari, 2001), teaching them self-management skills as early as possible, and let them work in groups as often as possible. For confirmed procrastinators, university should offer counselling (Schouwenburg et al., 2004).

The study at hand aimed at investigating the cognitive process preceding concrete preparation measures for exams. It did not focus on the behaviour itself. This may be a shortcoming, which will be addressed in an upcoming study. However, as the paper at hand was particularly interested in the effects of experience and procrastination on implementation intentions, not including behaviour seems not to be an issue. Furthermore, this paper investigated a rather special behaviour, that is preparing for exams. This behaviour is complex on the one hand and somewhat constrained by external conditions on the other hand. Hence, the generalizability of the results could be limited to behaviours with similar characteristics. Also, the study did not investigate indirect effects. Moderating effects may exist when using TPB in concert with procrastination and implementation intentions (Van Hooft et al., 2005); hence, such effects should be accounted for in future studies dealing with the behaviour in question. The paper at hand only used global, self-reported measures - these should be compared to more objective ones in the future. Furthermore, the study at hand was conducted at a German university. As educational systems differ a lot - even across Europe - larger, multi-country samples are very likely to provide more insight into the topic. The same is true for the method applied in this study which is quantitative in nature. Beyond doubt, cognitive-oriented research especially with respect to complex behaviour can benefit from a multi-method research agenda such as diaries or involvement in courses.

\section{Limitation}

The standardized weightings of regression between subjective norms and goal intention as well as between goal intention and implementation have a value of 1 . This represents a rather high value, but does not significantly exceed the value of 1 or 2 (Bühner, 2004, p.217).

The explained variance of the terms "goal intention" and "implementation intention" is surprisingly high for a TBP-model with values of 0.85 and 0.75 . A verification of the results in a further study is therefore mandatory.

Nevertheless, the statistical approach could also run the risk of wrong or uncertain specifications as Kline (2011) describes in the chapter "How to Fool Yourself with SEM" of his book. Examples for problems could be the "use of 
psychometrically inadequate measures" (Kline, 2011, p. 357) or the lack of a "sufficient number of indicators of latent variables" (Kline, 2011, p. 358). Further studies with revised measures and variables are reasonable.

Further problems could occur, according to Kline (2011), in the area of screening the data, like missing data accuracy, wrong assumptions, ignoring of interdependencies, etc. (Kline, 2011, pp. 359 - 361).More critical aspects could be seen in the stages of analysis and respecification as well as in the area of interpretation. Typical problems are in the area of start values, when the initial estimates prove to be wrong, if the checking of the accuracy of computer syntaxes, the recognition of empirical underidentification, or the checking of the admissibility of results is disregarded (Kline, 2011, pp. 361 - 363). For the paper at hand, no evidence indicating missing data accuracy or misinterpretation has been found.

\section{References}

Aarts, H., \&Dijksterhuis, A. (2000). Habits as Knowledge Structures: Automaticity in Goal-Directed Behaviour.Journal of Personality and Social Psychology, 78(1), 53-63. http://dx.doi.org/10.1037/0022-3514.78.1.53

Aarts, H., Verplanken, B., \&Knippenberg, A. (1998). Predicting Behaviour From Action in the Past: Repeated Decision Making or a Matter of Habit?. Journal of Applied Social Psychology, 28(15), 1355-1374. http://dx.doi.org/10.1111/j.1559-1816.1998.tb01681.x

Achtziger, A., \& Gollwitzer, P.M. (2006). Motivation und Volition im Handlungsverlauf. in: Heckhausen, J., \& Heckhausen, H. (Eds.). Motivation und Handeln(3rd. ed), Berlin.

Aitken, M. E. (1982). A Personality Profile of the College Student Procrastinator (Doctoral dissertation). University of Pittsburgh. Dissertation Abstracts International. (43, 722)

Ajzen, I. (1988). Attitudes, Personality, and Behaviour. Buckingham.

Ajzen, I. (1991). Theory of Planned Behaviour. Organizational Behaviour and Human Decision Processes, 50(2),179-211. http://dx.doi.org/10.1016/0749-5978(91)90020-T

Ajzen, I. (2002). Residual Effect of Past on Later Behaviour: Habituation and Reasoned Action Perspectives. Personality and Social Psychology Review6( 2), 107-122. http://dx.doi.org/10.1207/S15327957PSPR0602_02

Ajzen, I. (2005). Attitudes, Personality and Behaviour(2nd ed.), Maidenhead.

Ajzen, I., \& Madden, T.J. (1986). Prediction of Goal-directed Behaviour: Attitudes, Intentions, and Perceived Behavioural Control. Journal of Experimental Social Psychology, 22(5), 453-474. http://dx.doi.org/10.1016/0022-1031(86)90045-4

Armitage, C.H. (2004). Evidence That Implementation Intentions Reduce Dietary Fat Intake: A Randomized Trial. Health Psychology, 23(3), 319-323. http://dx.doi.org/10.1037/0278-6133.23.3.319

Armitage, C.H., \& Conner, M. (1997).Distinguishing Perceptions of Control from Self-efficacy: Predicting Consumption of a Low Fat Diet Using the Theory of Planned Behaviour (Unpublished manuscript). University of Leeds, UK.

Armitage, C.H., \& Conner, M. (2001). Efficacy of the Theory of Planned Behaviour: A meta-analytic review. British Journal of Social Psychology, 40(4), 471-499. http://dx.doi.org/10.1348/014466601164939

Bagozzi, R.P. (1992). The Self-regulation of Attitudes, Intentions, and Behaviour. Social Psychology Quarterly, 55(2), 178-204. http://dx.doi.org/10.2307/2786945

Bagozzi, R. P., \& Kimmel, S. K. (1995). A Comparison of Leading Theories for the Prediction of Goal-directed Behaviours. British Journal of Social Psychology, $34(4), \quad 437-461$. http://dx.doi.org/10.1111/j.2044-8309.1995.tb01076.x

Bagozzi, R.P., \&Warshaw, P.R. (1992). An Examination of the Etiology of the Attitude-Behaviour Relation for Goal-directed Behaviors. Multivariate Behavioural Research, 27( 4), 601-634. http://dx.doi.org/10.1207/s15327906mbr2704_6

Baloğlu, M. (2003). Individual Differences in Statistics Anxiety among College Students. Personality and Individual Differences, 34(5), 855-865. http://dx.doi.org/10.1016/S0191-8869(02)00076-4

Bamberg, S. (1996). Integration des Konstrukts Habit in die Theorie des geplanten Verhaltens. Zeitschrift für Sozialpsychologie, 27(4), 295-310.

Bandura, A. (1982). Self-efficacyMechanism in Human Agency. American Psychologist. 37(2), 122-147. http://dx.doi.org/10.1037/0003-066X.37.2.122 
Baumeister, R.F., \&Scher, S.J. (1988). Self-defeating Behaviour Patterns Among Normal Individuals. Psychological Bulletin, 104(1), 3-22. http://dx.doi.org/10.1037/0033-2909.104.1.3

Beck, B. L., Koons, S. R., \&Milgrim, D. L. (2000). Correlates and Consequences of Behavioral Procrastination: The Effects of Academic Procrastination, Self-consciousness, Self-esteem and Self-Handicapping. Journal of Social Behavior and Personality, 15(5), 3-13. http://doi.apa.org/psycinfo/2002-10572-001

Bishop, J.B., Bauer, K.W.,Becker, E. T. (1998). A Survey of Counseling Needs of Male and Female College Students. Journal of College Student Development, 39(2), 205-210.

Boocock, S.P. (1972). An Introduction to the Sociology of Learning. Boston.

Brandstätter, V., Heimbeck, D., Malzacher, J.T., \&Frese, M. (2003). Goals Need Implementation Intentions: The Model of Action Phases Tested in the Applied Setting of Continuing Education. European Journal of Work and Organizational Psychology, 12(1), 37-59. http://dx.doi.org/10.1080/13594320344000011

Bühner, M. (2004). Einführung in die Test- und Fragebogenkonstruktion.Pearson Studium, 217.

Chen, H., \& Lan, W. (1998). Adolescents' Perceptions of their Parents' Academic Expectations: Comparison of American, Chinese-American, and Chinese High School Students. Adolescence, 33, 385-390.

Cohen, J. (1992). A Power Primer. Psychological Bulletin, 112(1), 155-159. http://dx.doi.org/10.1037/0033-2909.112.1.155

Day, V., Mensink, D., \& O’Sullivan, M. (2000). Patterns of Academic Procrastination. Journal of College Reading and Learning, 30(2), 120-134.

Dewitte, S., \& Lens, W. (2000). Procrastinators Lack a Broad Action Perspective. European Journal of Personality, 14(2), 121-140. http://dx.doi.org/10.1002/(SICI)1099-0984(200003/04)14:2<121::AID-PER368>3.0.CO;2-\#

Digman, J. M. (1990). Personality Structure: Emergence of the Five-factor Model.Annual Review of Psychology, 41, 417-446. http://dx.doi.org/10.1146/annurev.ps.41.020190.002221

Dolan, B. (1999). From the Field: Cognitive Profiles of First Nations and Caucasian Children Referred for Psychoeducational Assessment. Canadian Journal of School Psychology, 15(1), 63-71. http://dx.doi.org/10.1177/082957359901500105

Eagly, A.H., \&Chaiken, S. (1993). The Psychology of Attitudes. Orlando.

Ehrman, M.E., \&Oxford, R.L. (1995). Cognition Plus: Correlates of Language Learning Success. The Modern Language Journal,79(1), 67-89. http://dx.doi.org/10.1111/j.1540-4781.1995.tb05417.x

Evans, R. I., Dratt, L. M., Raines, B. E., \& Rosenberg S. S. (1988). Social Influences on Smoking Initiation: Importance of Distinguishing Descriptive versus Mediating Process Variables. Journal of Applied Social Psychology, 18(11), 925-943. http://dx.doi.org/10.1111/j.1559-1816.1988.tb01184.x

Fazio, R. H., \& Williams, C. J. (1986). Attitude Accessibility as a Moderator of the Attitude-Perception and Attitude-Behaviour Relations: An Investigation of the 1984 Presidential Election. Journal of Personality and Social Psychology, 51(3), 505-514. http://dx.doi.org/10.1037/0022-3514.51.3.505

Ferrari, J. R. (1992). Procrastinators and Perfect Behavior: An Exploratory Factor Analysis of Self-presentation, Self-Awareness, and Self-handicapping Components. Journal of Research in Personality, 26(1), 75-84. http://dx.doi.org/10.1016/0092-6566(92)90060-H

Ferrari, J.R. (2001). Getting Things Done on Time: Conquering Procrastination. C.R. Snyder (Ed.): Coping with Stress: Effective People and Processes. Oxford, 30-46.

Ferrari, J. R., \& Emmons, R. A. (1994). Procrastination as Revenge: Do People Report Using Delays as a Strategy for Vengeance?.Personality and Individual Differences, 17(4), 539-544. http://dx.doi.org/10.1016/0191-8869(94)90090-6

Ferrari, J.R., \& Emmons, R.A. (1995). Methods of Procrastination and their Relation to Self-control and Self-reinforcement: An Exploratory Study. Journal of Social Behaviour\& Personality, 10(1), 135-142.

Ferrari, J. R., Johnson, J. L., \& McCown, W. G. (1995). Procrastination and Task Avoidance: Theory, Research, and Treatment. New York.

Ferrari, J.R., Keane, S.M., Wolfe, R.N., \& Beck, B.L. (1998). The Antecedents and Consequences of Academic Excuse-making: Examining Individual Differences in Procrastination. Research in Higher Education, 39(2), 199-215. http://dx.doi.org/10.1023/A:1018768715586 
Fishbein, M., \& Ajzen, I. (1975). Belief, Attitude, Intention, and Behaviour: An Introduction to Theory and Research.(Reading)

Fritzsche, B.A., Rapp Young, B., \& Hickson, K.C. (2003). Individual Differences in Academic Procrastination Tendency and Writing Success. Personality and Individual Differences, 35(7), 1549-1557. http://dx.doi.org/10.1016/S0191-8869(02)00369-0

Gal, I./Ginsburg, L. (1994). The Role of Beliefs and Attitudes in Learning Statistics: Towards an Assessment Framework. Journal of Statistics Education, 2(2), 1-54.

Goldberg, L. R. (1993). The Structure of Phenotypic Personality Traits.American Psychologist, 48(1), $26-34$. http://dx.doi.org/10.1037/0003-066X.48.1.26

Gollwitzer, P. M. (1990). Action Phases and Mind-sets.Higgins, E.T., \& Sorrentino, R.M. (Eds.): Handbook of Motivation and Cognition: Foundations of Social Behaviour (Vol. 2). (pp. 53-92) New York.

Gollwitzer, P.M. (1993). Goal Achievement: The Role of Intentions. European Review of Social Psychology, 4, 141 185. http://dx.doi.org/10.1080/14792779343000059

Gollwitzer, P. M. (1996). The Volitional Benefits of Planning. Gollwitzer, P.M., \& Bargh, J.A. (Eds.): The Psychology of Action: Linking Cognition and Motivation to Behaviour.(pp. 287-312) New York.

Gollwitzer, P. M. (1999). Implementation Intentions: Strong Effects of Simple Plans. American Psychologist, 54(7), 493-503. http://dx.doi.org/10.1037/0003-066X.54.7.493

Gollwitzer, P.M., Bayer, U.C., \&McCulloch, K.C. (2005). The Control of the Unwanted. Bargh, J.A., Uleman, J.S., Hassin, R.R. (Eds.): The New Unconscious. (pp. 485-515) Oxford.

Gollwitzer, P.M., \&Brandstätter, V. (1997). Implementation Intentions and Effective Goal Pursuit. Journal of Personality and Social Psychology 73(1), 186-199. http://dx.doi.org/10.1037/0022-3514.73.1.186

Gollwitzer, P.M., \&Sheeran, P. (2006). Implementation Intentions and Goal Achievement: A Meta-analysis of Effects and Processes. Advances in Experimental Social Psychology, 38, 69-120. http://dx.doi.org/10.1016/S0065-2601(06)38002-1

Gollwitzer, P.M., \& Sheeran, P. (2009). Self-regulation of Consumer Decision Making and Behaviour: The Role of Implementation Intentions. Journal of Consumer Psychology, 19(4), $593 \quad-\quad 607$. http://dx.doi.org/10.1016/j.jcps.2009.08.004

Graham, S., MacArthur, C., \& Schwartz, S. (1995). Effects of Goal-setting and Procedural Facilitation on the Revising Behaviour and Writing Performance of Students with Writing and Learning-problems. Journal of Educational Psychology, 87(2), 230-240. http://dx.doi.org/10.1037/0022-0663.87.2.230

Guthrie, C.A., \&Sparks, P. (1997). Perceived Behavioural Control: Interpretation of the Construct and Elicitation of its Proximal Predictors. (Unpublished manuscript)Institute of Food Research.

Hampson, S. (1999). State of the Art: Personality.The Psychologist, 12(6), 284-288.

Heckhausen, H., \& Gollwitzer, P.M. (1987). Thought Contents and Cognitive Functioning in Motivational versus Volitional States of Mind. Motivation and Emotion, 11(2), 101-120. http://dx.doi.org/10.1007/BF00992338

Henderson, A. (1988). Parents are School's Best Friends. Phi Delta Kappan. (149-153)

Hicks, L., Murphy, A.M., \& Patrick, H. (1995). The Relationship Between Social and Achievement Goals in Early Adolescence.(Conference Paper)Biennial Meeting of the Society for Research in Child Development, April 1995, Indianapolis.

Hill, M.B., Hill, D.A., Chabot, A.E., \& Barral, J.F. (1978). A Survey of College Faculty and Student Procrastination. College Student Journal, 12(3), 256-262.

Howell, A.J., Watson, D.C., Powell, R.A., \&Buro, K. (2006). Academic Procrastination: The Pattern and Correlates of Behavioural Postponement. Personality and Individual Differences, 40(8), 1519-1530. http://dx.doi.org/10.1016/j.paid.2005.11.023

Hrisos, S., Eccles, M., Johnston, M., Francis,J., Kaner,E.F.S., Steen, N., \& Grimshaw, J. (2008). Developing the Content of Two Behavioural interventions: Using Theory-based Interventions to Promote GP Management of Upper Respiratory Tract Infection Without Prescribing Antibiotics \#1. BMC Health Services Research 2008, 8(11), 1-8. http://dx.doi.org/10.1186/1472-6963-8-11 
Kalafatis, S.P., Pollard, M., East, R., \& Tsogas, M.H. (1999). Green Marketing and Ajzen's Theory of Planned Behaviour: a Cross-market Examination. Journal of Consumer Marketing, 16(5),441-460. http://dx.doi.org/10.1108/07363769910289550

Kidwell, B., \& Jewell, R. (2008). The Influence of Past Behaviour on Behavioural Intent - An Information-Processing Explanation.Psychology \& Marketing, 25(12), 1151-1166. http://dx.doi.org/10.1002/mar.20258

Kim, M., \& Hunter, J. (1993). Relationships Among Attitudes, Intentions and Behaviour. Communication Research, 20(3), 331-364. http://dx.doi.org/10.1177/009365093020003001

Kistan, C. (2002). Recognition of Prior Learning: A Challenge to Higher Education. South African Journal of Higher Education, 16(1), 169-173. http://dx.doi.org/10.4314/sajhe.v16i1.25288

Klassen, R.M., Krawchuk, L.L., \&Rajani, S. (2008). Academic Procrastination of Undergraduates: Low Self-efficacy to Self-regulate Predicts Higher Levels of Procrastination. Contemporary Educational Psychology, 33(4), 915-931. http://dx.doi.org/10.1016/j.cedpsych.2007.07.001

Kline, R. B. (2011). Principles and practice of structural equation modelling. New York: Guilford.

Koretz, G. (1997). The Sheepskin Paradox: College Grads in Lower-level Jobs. Business Week, 6 October 1997. [Online] Available: http://www.businessweek.com/archives/1997/b3547052.arc.htm

Knussen, C., Yule, F., MacKenzie, J., Wells, M. (2004). An analysis of Intentions to Recycle Household Waste: The Roles of Past Behaviour, Perceived Habit, and Perceived Lack of Facilities. Journal of Environmental Psychology, 24(2), 237-246. http://dx.doi.org/10.1016/j.jenvp.2003.12.001

Kuhl, J. (1994). A Theory of Action and State orientations. Kuhl, J./Beckmann, J. (Eds.): Volition and Personality: Action versus State Orientation.(6-46) Göttingen.

Lay, C.H. (1986). At Last, My Research Article on Procrastination.Journal of Research in Personality, 20(4),474-495. http://dx.doi.org/10.1016/0092-6566(86)90127-3

Lay, C. H., \& Brokenshire, R. (1997). Conscientiousness, Procrastination, and Person-task Characteristics in Job Searching by Unemployed Adults. Current Psychology, 16(1), 83-96. http://dx.doi.org/10.1007/s12144-997-1017-9

Lay, C.H., \& Burns, P. (1991). Intentions and Behaviour in Studying for an Examination: The Role of Trait Procrastination and its Interaction with Optimism. Journal of Social Behaviour and Personality, 6(3), 605-617.

Lay, C.H., Knish, S., \& Zanatta, R. (1992). Self-handicappers and Procrastinators: A Comparison of Their Practice Behaviour Prior to an Evaluation. Journal of Research in Personality, 26(3), 242-257. http://dx.doi.org/10.1016/0092-6566(92)90042-3

Leone, L., Perugini, M., \& Ercolani, A.P. (1999). A Comparison of Three Models of Attitude-Behaviour Relationships in the Studying Behaviour Domain. European Journal of Social Psychology, 29(2-3),161-189. http://dx.doi.org/10.1002/(SICI)1099-0992(199903/05)29:2/3<161::AID-EJSP919>3.0.CO;2-G

Lloyd, K.E. \&Knutzen, N.J. (1967). A Self-paced Programmed Undergraduate Course in the Experimental Analysis of Behavior. Journal of Applied Behavior Analysis, 2(2), 125-133. http://dx.doi.org/10.1901/jaba.1969.2-125

Manstead, A.S.R., \& Van Eekelen, S.A.M. (1998). Distinguishing Between Perceived Behavioural Control and Self-efficacy in the Domain of Academic Achievement Intentions and Behaviors. Journal of Applied Social Psychology, 28(15), 1375-1392. http://dx.doi.org/10.1111/j.1559-1816.1998.tb01682.x

McCrae, R. R., \&John, O. P. (1992). An Introduction to the Five-Factor Model and its Applications. Journal of Personality, 60(2), 175-215. http://dx.doi.org/10.1111/j.1467-6494.1992.tb00970.x

McVea, J.F. (2009). A Field Study of Entrepreneurial Decision-making and Moral Imagination. Journal of Business Venturing, 5, 491-504. http://dx.doi.org/10.1016/j.jbusvent.2008.07.003

Miller, W.R. (1998). Enhancing Motivation for Change. In W.R. Miller \& N. Heather (Eds), Treating Addictive Behaviours, 2nd edn. New York, pp. 121-132.

Miller,W. R. \&Rollnick, S. (1991). Motivational Interviewing: Preparing People to Change Addictive Behavior. New York.

Miller, W.R.\&Rollnick, S. (2009). Ten Thing that Motivational Interviewing is not. Behavioural and Cognitive Psychotherapy, 37(2), 129-140. http://dx.doi.org/10.1017/S1352465809005128 
Milne, S., Orbell, S., \& Sheeran, P. (2002). Combining Motivational and Volitional Interventions to Promote Exercise Participation: Protection Motivation Theory and Implementation Intentions. British Journal of Health Psychology, 7(2), 163-184. http://dx.doi.org/10.1348/135910702169420

Morgan, M. (1985). Self-monitoring of Attained Subgoals in Private Study. Journal of Educational Psychology, 77(6), 623-630. http://dx.doi.org/10.1037/0022-0663.77.6.623

Murrell, K.L., \& Bishop, R.W. (1995). The Learning Models for Managers: A Tool to facilitate Learning. Sims, R.R., \&Sims, S.J. (Eds.). The Importance of Learning Styles: Understanding the Implications for Learning, Course Design, and Education.(179-192) Westport.

Newstead, S. (1998). Individual Differences in Student Motivation. Brown, S., Armstrong, S., \&Thompson, G. (Eds.). Motivating Students.(189-199) London.

Orbell, S., \&Sheeran, P. (2000). Motivational and Volitional Processes in Action Initiation: A Field Study of the Role of Implementation Intentions. Journal of Applied Social Psychology, 30(4), 780-797. http://dx.doi.org/10.1111/j.1559-1816.2000.tb02823.x

Orbell, S., Hodgkins, S., \&Sheeran, P. (1997). Implementation Intentions and the Theory of Planned Behaviour. Personality and Social Psychology Bulletin, 23(9), 945-954. http://dx.doi.org/10.1177/0146167297239004

Ouellette, J.\&Wood, W. (1998). Habit and Intention in Everyday Life: The Multiple Processes by Which Past Behaviour Predicts Future Behaviour. Psychological Bulletin, 124(1), 54-74. http://dx.doi.org/10.1037/0033-2909.124.1.54

Owens, S.G., Bowman, C.G., \& Dill, C.A. (2008). Overcoming Procrastination: The Effect of Implementation Intentions. Journal of Applied Social Psychology, 38(2), 366-384. http://dx.doi.org/10.1111/j.1559-1816.2007.00309.x

Owens, A. M., \& Newbegin, I. (1997). Procrastination in High school Achievement: A Causal Structural Model. Journal of Social Behavior and Personality, 12(4), 869-887.

Oxford Online Dictionary. (2011). Definition of Behaviour. Retrieved October 23, 2011. [Online] available: http://oxforddictionaries.com/definition/behaviour

Pearson. (2011). Pearson Foundation Community College Student Survey - Summary of Results; [Online] available: http://www.pearsonfoundation.org/education-leadership/research/community-college-survey.html

Phillips, P., Abraham, C., \& Bond, R. (2003). Personality, Cognition, and University Students' Examination Performance. European Journal of Personality,17(6), 435-448. http://dx.doi.org/10.1002/per.488

Powers, T. A., Koestner, R., \& Topciu, R. A. (2005). Implementation Intentions, Perfectionism, and Goal Progress: Perhaps the Road to hell is paved with Good Intentions. Personality and Social Psychology Bulletin, 31(7), 902 - 912. http://dx.doi.org/10.1177/0146167204272311

Prentice, G.R., Caska, B.A., \& McLaughlin, C.G. (2009). Examining Psychology Undergraduates' Statistics Results Using the Theory of Planned Behaviour and Background Factors. The Irish Journal of Psychology, 30(2), 161-170.

Pressley, M., Yokoi, L., Van Meter, P., Van Etten, S., \& Freebern, G. (1997). Some of the Reasons Why Preparing for Exams Is So Hard: What Can Be Done to Make It Easier?. Educational Psychology Review, 9(1), 1-38. http://dx.doi.org/10.1023/A:1024796622045

Prochaska, J.O., DiClemente, C.C., Velicer, W.F., Ginpil, S., and Norcross, J.C. (1985). Predicting Change in Smoking Status for Self-changers. Addictive Behaviors, 10(4), pp. 395-406. http://dx.doi.org/10.1016/0306-4603(85)90036-X

Prochaska, J.O., DiClemente, C.C., Norcross, J.C. (1992). In Search of how People Change: Applications to Addictive Behaviors. American Psychologist, 47(9), 1102-1114. http://dx.doi.org/10.1037/0003-066X.47.9.1102

Rhodes, R., Courneya, K. (2003). Modelling the Theory of Planned Behaviour and Past Behaviour. Psychology, Health \& Medicine, 8(1), 57-69. http://dx.doi.org/10.1080/1354850021000059269

Rise, J., Thompson, M., \& Verplanken, B. (2003). Measuring Implementation Intentions in the Context of the Theory of Planned Behaviour. Scandinavian Journal of Psychology, 44(2), 87-95. http://dx.doi.org/10.1111/1467-9450.00325

Roig, M., \& DeTommaso, L. (1995). Are College Cheating and Plagiarism Related to Academic Procrastination? Psychological Reports, 77, 691-698. http://dx.doi.org/10.2466/pr0.1995.77.2.691

Rothblum, E. D., Solomon, L. J., \& Murakami, J. (1986). Affective, Cognitive, and Behavioral Differences Between High and Low Procrastinators. Journal of Counseling Psychology, 33(4), 387-394. http://dx.doi.org/10.1037/0022-0167.33.4.387 
Rotenstein, A., Davis, H.Z., \& Tatum, L. (2009). Early Birds versus Just-in-Timers: The effect of Procrastination on Academic Performance of Accounting Students. Journal of Accounting Education, 27(4), 223-232. http://dx.doi.org/10.1016/j.jaccedu.2010.08.001

Schouwenburg, H.C. (2004). Procrastination in Academic Settings: General Introduction. Schouwenburg, H.C., Lay, C.H., Pychyl, T.A., \& Ferrari, J.R. (Eds.).Counseling the Procrastinator in Academic Settings.(3-18) Washington D.C..

Schouwenburg, H.C., Lay, C.H., Pychyl, T.A., \& Ferrari, J.R.(Eds.). Counseling the Procrastinator in Academic Settings. Washington D.C.

Schwartz, G. E. (1976). What is Doing the Teaching in PSI Courses. In L. E. Fraley \& E. A. Vargas (Eds.), Behavior Research and Technology in Higher Education, 35-40. Gainesville, University of Florida.

Sheeran, P. (2002). Intention-behaviour Relations: A Conceptual and Empirical Review.European Review of Social Psychology, 12, 1-36. http://dx.doi.org/10.1080/14792772143000003

Sheeran, P., Webb, T.L., \& Gollwitzer, P.M. (2005). The Interplay Between Goal Intentions and Implementation Intentions. Personality and Social Psychology Bulletin, 31(1), 87-98. http://dx.doi.org/10.1177/0146167204271308

Sheeran, P., \& Orbell, S. (2000). Using Implementation Intentions to Increase Attendance for Cervical Cancer Screening. Health Psychology,19(3), 283-289. http://dx.doi.org/10.1037/0278-6133.19.3.283

Sheppard, B.H., Hartwick, J., \& Warshaw, P.R. (1988). The Theory of Reasoned Action: A Meta-analysis of Past Research With Recommendations for Modifications and Future Research. Journal of Consumer Research, 15(3), 325-343. http://dx.doi.org/10.1086/209170

Sirois, F.M. (2004). Procrastination and Intentions to Perform Health Behaviors: The Role of Self-efficacy and the Consideration of Future Consequences. Personality and Individual Differences, 37(1), 116-128. http://dx.doi.org/10.1016/j.paid.2003.08.005

Solomon, L. J., \& Rothblum, E. D. (1984). Academic Procrastination: Frequency and Cognitive-Behavioral Correlates. Journal of Counseling Psychology, 31(4), 503-509. http://dx.doi.org/10.1037/0022-0167.31.4.503

Sommer, L. (2010). Prokrastination (Unpublished Working Paper). Department of Business Administration and Engineering at Albstadt-Sigmaringen University.

Sutton, S. (1998). Predicting and Explaining Intentions and Behaviour: How Well are we Doing?.Journal of Applied Social Psychology, 28(15), 1317-1338. http://dx.doi.org/10.1111/j.1559-1816.1998.tb01679.x

Sutman, F. (1992). Science Content Errors: An Issue of Immediate Concern. Journal of Research in Science Teaching, 29(5),437-439. http://dx.doi.org/10.1002/tea.3660290501

Tesser, A. ,\& Shaffer, D.R. (1990). Attitudes and Attitude Change. Annual Review of Psychology, 41, 479-523. http://dx.doi.org/10.1146/annurev.ps.41.020190.002403

Triandis, H.C. (1980). Values, Attitudes, and Interpersonal Behaviour. Howe, H., \& Page, M. (Eds.). Nebraska Symposium on Motivation, 27, 195-259.

Tuckman, B.W. (1991). The Development and Concurrent Validity of the Procrastination Scale. Educational and Psychological Measurement, 51(2),473-480. http://dx.doi.org/10.1177/0013164491512022

Tversky, A., \& Kahneman, D. (1974). Judgment under Uncertainty: Heuristics and Biases. Science 27, 185, 1124-1131. http://dx.doi.org/10.1126/science.185.4157.1124

Urdan, T.C., \&Maehr, M.L. (1995). Beyond a Two-Goal Theory of Motivation and Achievement: A Case for Social Goals. Review of Educational Research, 65(3), 213-243. http://dx.doi.org/10.3102/00346543065003213

Van Eerde, W. (2000). Procrastination: Self-regulation in Initiating Aversive Goals. Applied Psychology - An International Review, 49(3), 372-389.

Van Eerde, W. (2003). A Meta-analytically Derived Nomological Network of Procrastination. Personality and Individual Differences, 35(6), 1401-1418. http://dx.doi.org/10.1016/S0191-8869(02)00358-6

Van Hooft, E.A.J., Born, M.P., Taris, T.W., Van der Flier, H., \&Blonk, R.W.B. (2005). Bridging the Gap Between Intentions and Behaviour: Implementation Intentions, Action Control, and Procrastination. Journal of Vocational Behaviour, 66(2), 238-256. http://dx.doi.org/10.1016/j.jvb.2004.10.003 
Verplanken, B., \&Faes, S. (1999). Good Intentions, Bad Habits, and Effects of Forming Implementation Intentions on Healthy Eating. European Journal of Social Psychology, 29(5-6), 591-604. http://dx.doi.org/10.1002/(SICI)1099-0992(199908/09)29:5/6<591::AID-EJSP948>3.0.CO;2-H

Vollmer, F. (1986). The Relationship Between Expectancy and Academic Achievement - How Can It Be Explained? British Journal of Educational Psychology, 56(1), 64-74. http://dx.doi.org/10.1111/j.2044-8279.1986.tb02646.x

Webb, T.L., Christian, J., \&Armitage, C.J. (2007). Helping Students Turn up for Class: Does Personality Moderate the Effectiveness of an Implementation Intention Intervention? Learning and Individual Differences, 17(4), 316-327. http://dx.doi.org/10.1016/j.lindif.2007.03.001

Webb, T.L., \&Sheeran, P. ( 2005). Integrating Concepts from Goal Theories to Understand the Achievement of Personal Goals. European Journal of Social Psychology, 35(1), 69-96. http://dx.doi.org/10.1002/ejsp.233

Weiber, R., \&Mühlhaus, D. (2010). Eine anwendungsorientierte Einführung in die Kausalanalyse mit Hilfe von AMOS, SmartPLS und SPSS.Springer Verlag, 1, 71-198.

Wentzel, K.R. (2005). Peer Relationships, Motivation, and Academic Performance at School. Elliot, A.J., \&Dweck, C.S. (Eds.). Handbook of Competence and Motivation.(279-296) New York.

Wesley, J. C. (1994). Effects of Ability, High School Achievement, and Procrastinatory Behavior on College performance. Educational and Psychological Measurement, 54(2), 404-408. http://dx.doi.org/10.1177/0013164494054002014

Winn, S. (2002). Student Motivation: A Socio-economic Perspective. Studies in Higher Education, 27(4), 445-457. http://dx.doi.org/10.1080/0307507022000011552

Wong, C., \&Mullan, B. (2009). Predicting Breakfast Consumption: An Application of the Theory of Planned Behaviour and the Investigation of Past Behaviour and Executive Function. British Journal of Health Psychology, 14(3), 489-504. http://dx.doi.org/10.1348/135910708X360719

Table 1. Constructs and measurement approach

Source: Own Illustration

\begin{tabular}{|c|c|c|c|}
\hline Construct & $\begin{array}{l}\text { No. of } \\
\text { items* }\end{array}$ & Scale $* *$ & Reference \\
\hline \multicolumn{4}{|c|}{ A. Constructs included into final analysis } \\
\hline 1. $\quad$ Attitudes & $2 / 2$ & 5-point Likert scale & Sheeran et al. (2005) \\
\hline 2. Social norm & $2 / 3$ & 5-point Likert scale & $\begin{array}{l}\text { Rhodes et al. (2006); } \\
\text { Gollwitzer et al. (2005) }\end{array}$ \\
\hline 3. PBC & $2 / 3$ & 5-point Likert scale & Hrisos et al. (2008) \\
\hline 4. Goal intention & $1 / 1$ & 5-point Likert scale & Gollwitzer et al. (1993) \\
\hline 5. Implementation intention & $4 / 4$ & 5-point Likert scale & $\begin{array}{l}\text { Hrisos et al. (2008); } \\
\text { Gollwitzer et al. (2003) }\end{array}$ \\
\hline 6. Procrastination & $19 / 19$ & 5-point Likert scale & Aitken (1982) \\
\hline 7. $\quad$ Experience & $1 / 3$ & 5-point Likert scale & Newly developed \\
\hline \multicolumn{4}{|c|}{ B. Constructs not included into final analysis } \\
\hline 8. Action vs. state orientation $* * *$ & & None & Kuhl (1990) \\
\hline
\end{tabular}

* - items actually used after pre-test as compared to original number of items

** - Ranging from 1 (Totally disagree) to 5 (Totally agree)

*** - State vs. action orientation was included into the final analysis 
Table 2. Variables included

\begin{tabular}{|l|l|l|}
\hline A. Latent variables - exogenous & Items & Residual \\
\hline V1: Attitudes & I 6 / I 7 & e-6 / e-7 \\
\hline V2: Social norm & I 8 / I 10 & e-8 / e-10 \\
\hline V3: PBC & I 11 / I 12 & e-11 / e-12 \\
\hline V4: Procrastination & I 16 & e-16 \\
\hline V5: Experience & I 15 & e-15 \\
\hline B. Latent variables - endogenous & & \\
\hline V6: Goal intention & I 1 & e-1 / c-1 \\
\hline V7: Implementation intention & I 2 / I 3 / I 17 / I 18 & e-2 / e-3 / e-17 / e-18 / c-2 \\
\hline
\end{tabular}

Table 3. Descriptive quality criteria

\begin{tabular}{|l|l|l|}
\hline Descriptive quality criteria & Threshold value & Computed value \\
\hline Root Mean Square Residual (RMR) & The smaller the better & 0.108 \\
\hline Goodness of Fit Index (GFI) & $\geq 0.9$ & 0.937 \\
\hline Adjusted Goodness of Fit Index (AGFI) & $\geq 0.9$ & 0.876 \\
\hline
\end{tabular}

Table 4. Fitness indices

\begin{tabular}{|l|l|l|}
\hline Incremental fitness indices & Threshold value & Computed value \\
\hline Normed Fit Index (NFI) & $\geq 0.9$ & 0.810 \\
\hline Comparative Fit Index (CFI) & $\geq 0.9$ & 0.876 \\
\hline Incremental Fit Index (IFI) & $\geq 0.9$ & 0.885 \\
\hline
\end{tabular}

Table 5. Results for hypotheses

\begin{tabular}{|l|l|l|}
\hline Hypothesis & CR & P \\
\hline H1a: Attitudes - Goal Intention & 1.524 & 0.144 \\
\hline H1b: Social norm - Goal Intention & 1.890 & 0.070 \\
\hline H1c: PBC - Goal Intention & 1.868 & 0.080 \\
\hline H2: Goal Intention - Implementation Intention & 2.663 & 0,008 \\
\hline H3: Experience - Implementation Intention & 1.322 & 0.202 \\
\hline H4: Procrastination - Implementation Intention & 1.860 & 0,082 \\
\hline
\end{tabular}

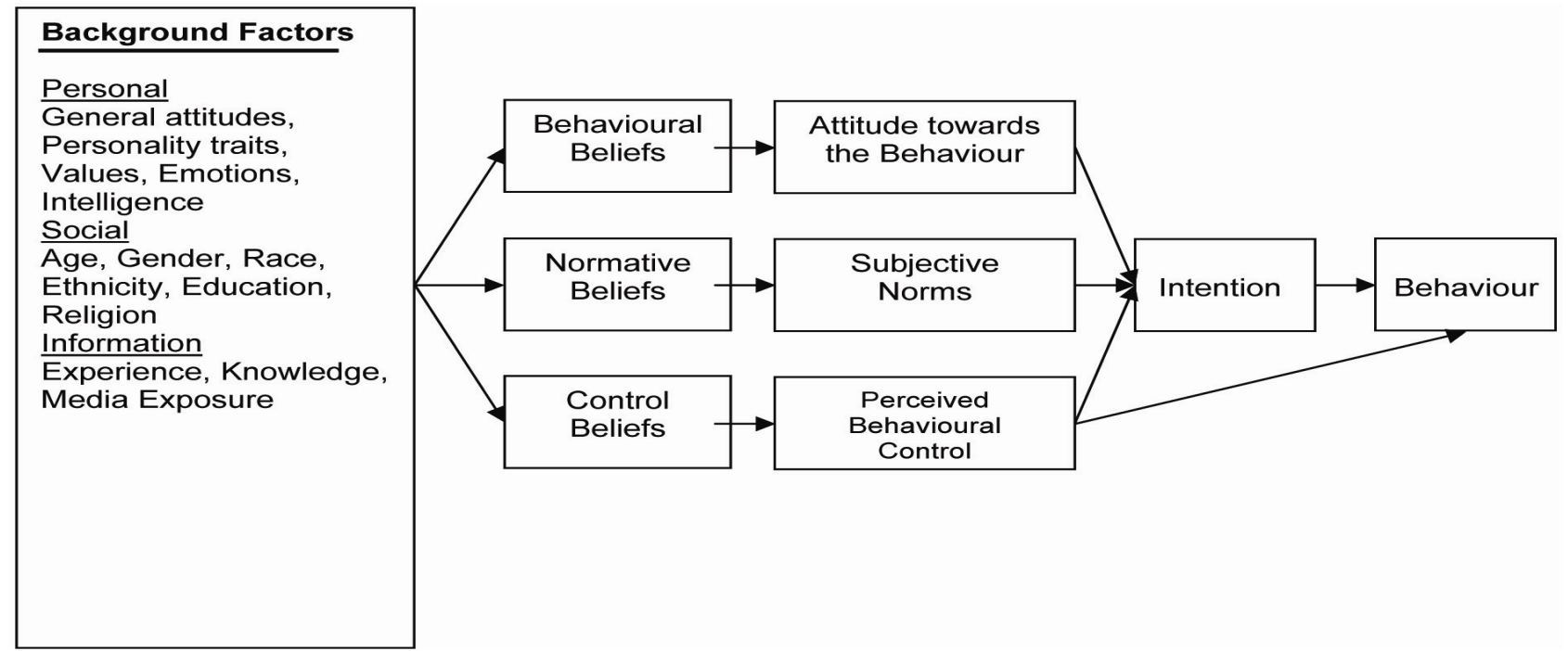

Figure 1. Theory of Planned Behaviour Source: Ajzen (2005), p. 135 - modified 


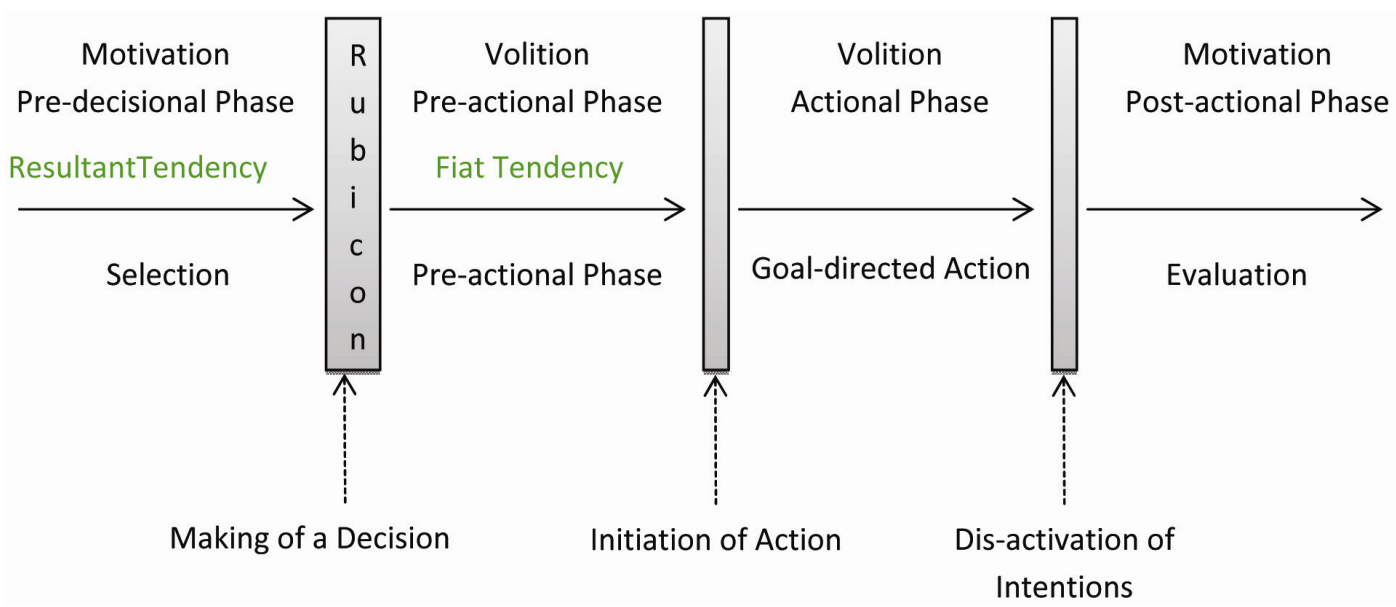

Figure 2. Rubicon model - modified

Source: Achtziger, \&Gollwitzer (2006), p. 278

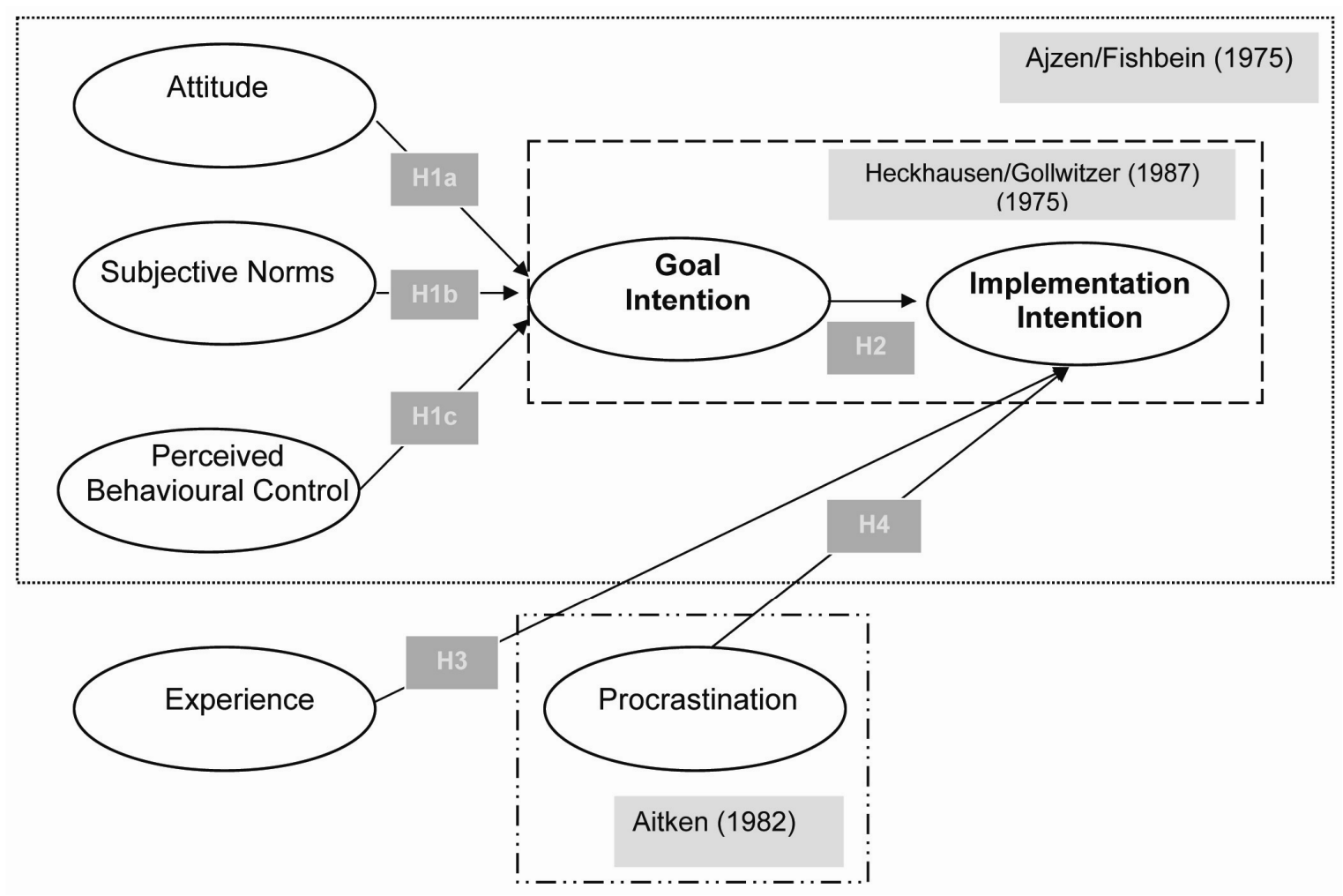

Figure 3. Research Model

Source: Own Illustration 


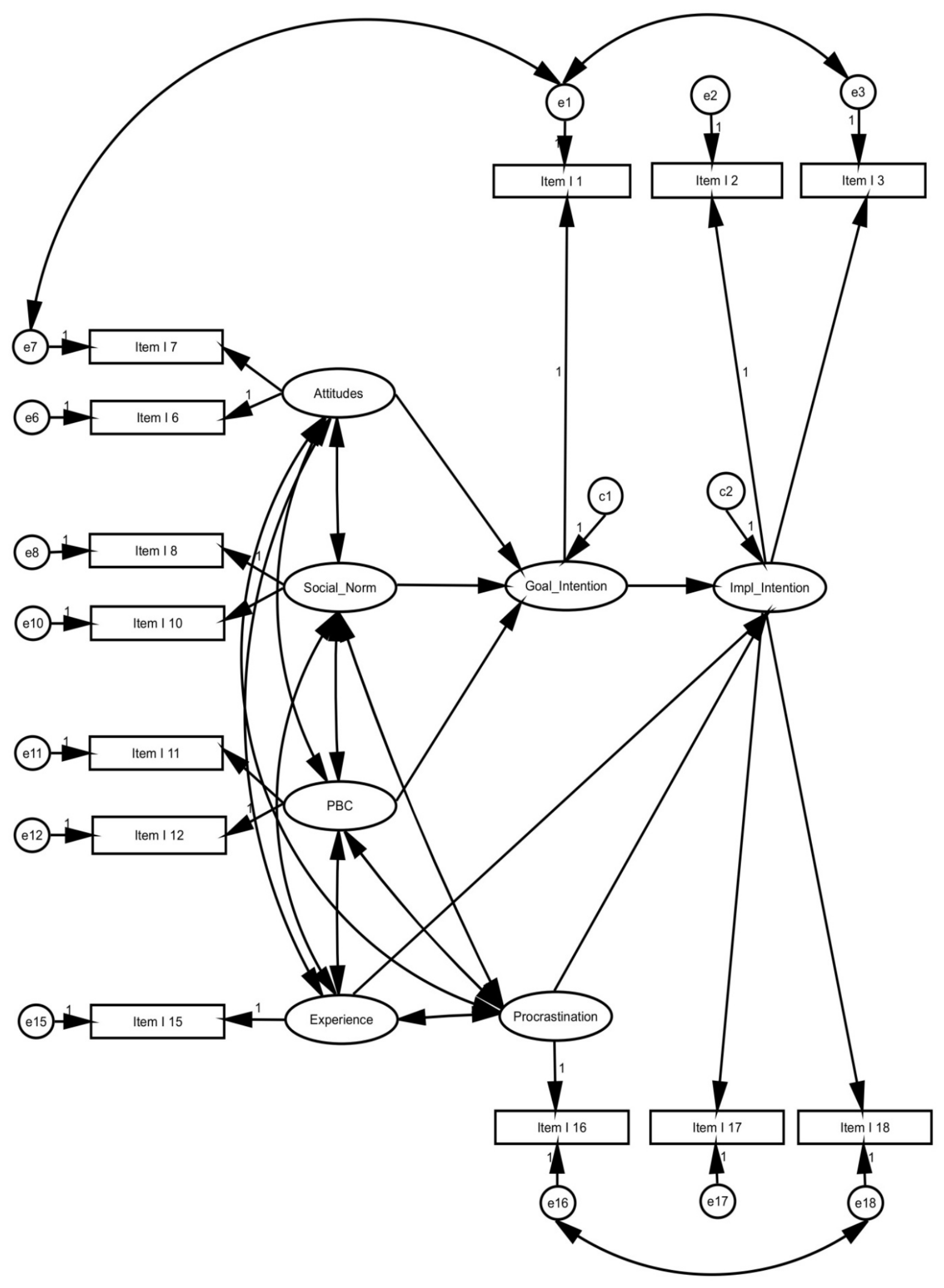

Figure 4. Path diagram -research model (including hypotheses H1 - H4) Source: Own illustration based on AMOS 17 


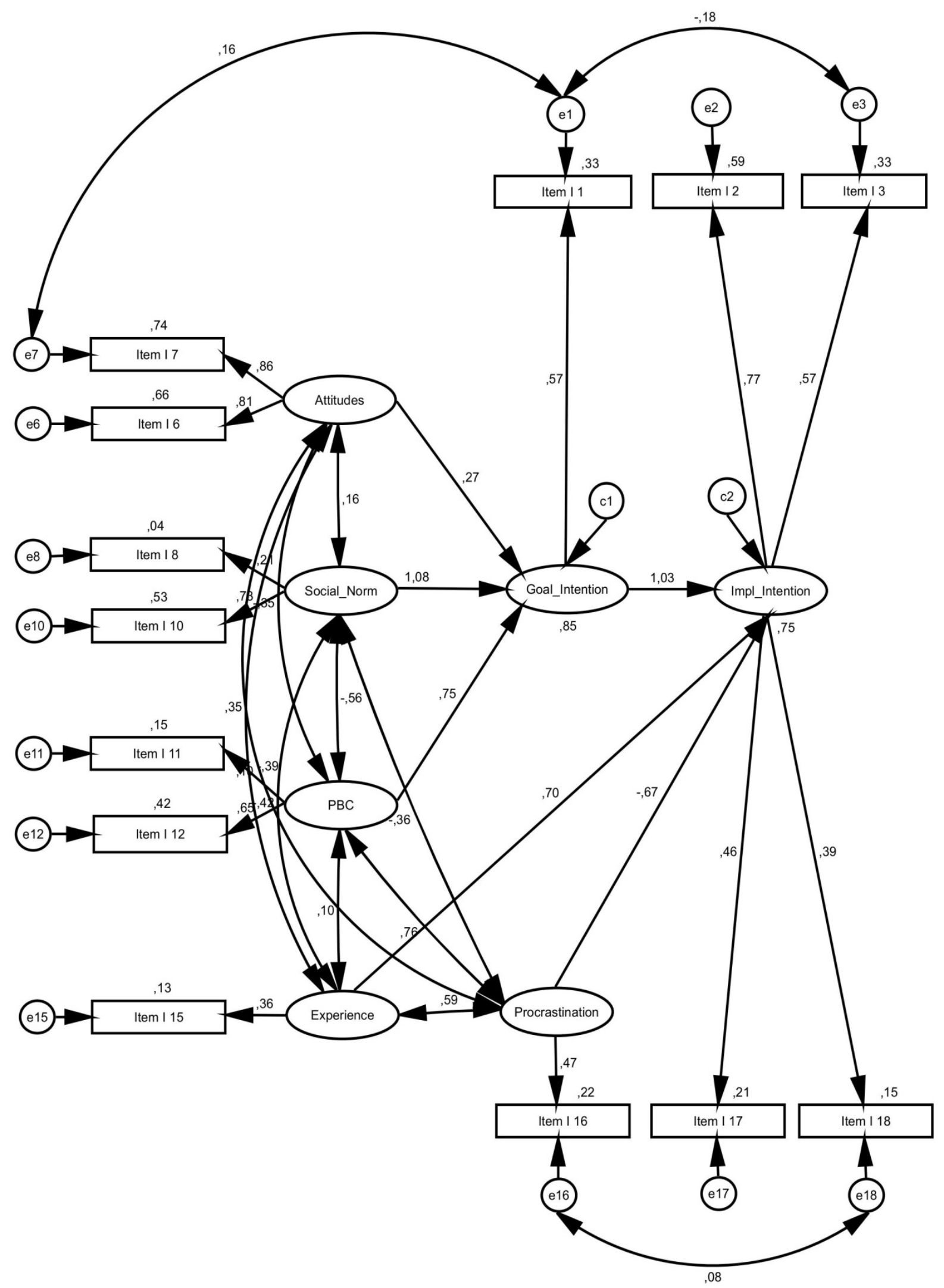

Figure 5. Path diagram including standardized coefficients (including hypotheses $\mathrm{H} 1-\mathrm{H} 4$ ) Source: Own illustration based on AMOS 17 


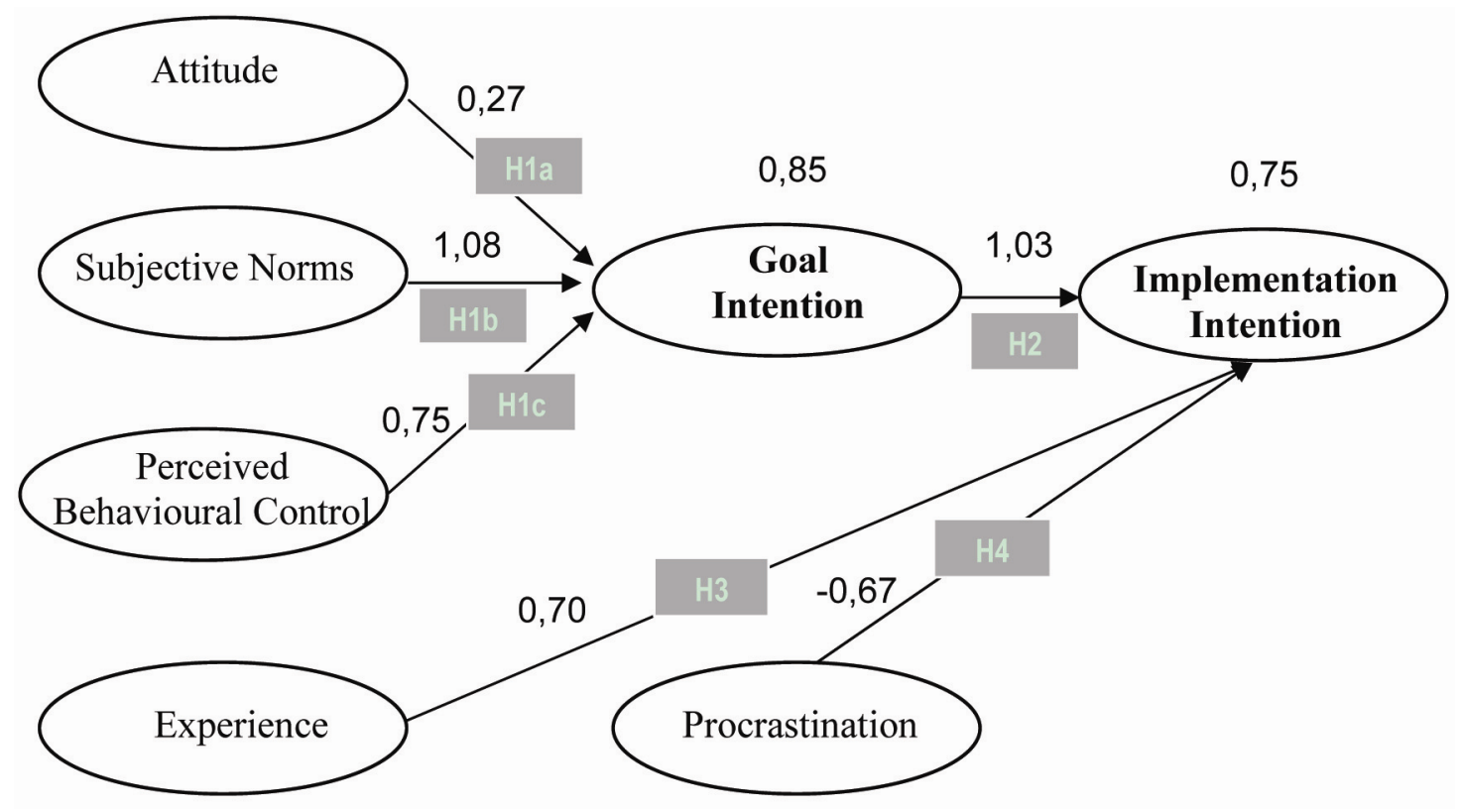

Figure 6. Research Model including causal effects

Source: Own Illustration 